\title{
$\beta$-Arrestin-Mediated Regulation of the Human Ether-a-go-go-Related Gene Potassium Channel
}

\author{
Matthew G. Sangoi, Shawn M. Lamothe, Jun Guo, Tonghua Yang, Wentao Li, \\ Ellen G. Avery, John T. Fisher, and Shetuan Zhang
}

Department of Biomedical and Molecular Sciences, Queen's University, Kingston, Ontario, Canada

Received December 23, 2016; accepted May 10, 2017

\begin{abstract}
The rapidly activating delayed rectifier $\mathrm{K}^{+}$channel $\left(\mathrm{I}_{\mathrm{Kr}}\right)$ is encoded by the human ether-a-go-go-related gene ( $h E R G$ ), which is important for the repolarization of the cardiac action potential. Mutations in hERG or drugs can impair the function or decrease the expression level of hERG channels, leading to long QT syndrome. Thus, it is important to understand hERG channel trafficking and its regulation. For this purpose, G protein-coupled receptors (GPCRs), which regulate a vast array of cellular processes, represent a useful route. The development of designer GPCRs known as designer receptors exclusively activated by designer drugs (DREADDs) has made it possible to dissect specific GPCR signaling pathways in various cellular systems. In the present study, by expressing an arrestin-biased M3 muscarinic receptorbased DREADD (M3D-arr) in stable hERG-expressing human
\end{abstract}

embryonic kidney (HEK) cells, we demonstrate that $\beta$-arrestin signaling plays a role in hERG regulation. By exclusively activating M3D-arr using the otherwise inert compound, clozapine-N-oxide, we found that M3D-arr activation increased mature hERG expression and current. Within this paradigm, M3D-arr recruited $\beta$-arrestin- 1 to the plasma membrane, and promoted phosphoinositide 3-kinase-dependent activation of protein kinase B (Akt). The activated Akt acted through phosphatidylinositol 3-phosphate 5-kinase and Rab11 to facilitate hERG recycling to the plasma membrane. Potential $\beta$-arrestin signaling-mediated increases in $\mathrm{hERG}$ and $\mathrm{I}_{\mathrm{Kr}}$ were also observed in hERG-HEK cells as well as in neonatal rat ventricular myocytes treated with the muscarinic agonist carbachol. These findings provide novel insight into hERG trafficking and regulation.

\section{Introduction}

The human ether-a-go-go-related gene ( $h E R G$ or $K C N H 2$ ) encodes the rapidly activating delayed rectifier $\mathrm{K}^{+}$current $\left(\mathrm{I}_{\mathrm{Kr}}\right)$ channel (Sanguinetti et al., 1995; Trudeau et al., 1995). A decrease in $\mathrm{I}_{\mathrm{Kr}}$ due to loss-of-function mutations or drug interactions can cause inherited or acquired long QT syndrome (LQTS), a cardiac electrical disorder characterized by a prolongation of QT intervals on an ECG (Curran et al., 1995; Keating and Sanguinetti, 2001; Kuryshev et al., 2005; Guo et al., 2007, 2009). Individuals with LQTS are predisposed to ventricular arrhythmias or even sudden death (Keating and Sanguinetti, 2001).

Mutations in hERG can decrease $\mathrm{I}_{\mathrm{Kr}}$ through various mechanisms (Zhou et al., 1998) with trafficking deficiency being one of the most frequent reasons (Anderson et al., 2006). Thus, rescue of mutant hERG trafficking is of clinical relevance. Due

This work was supported by the Natural Sciences and Engineering Research Council of Canada [Grant RGPIN 384368-13] to S.Z.

The authors declare that they have no conflicts of interest with the contents of this article.

http://doi.org/10.1124/mol.116.108035. to the critical role of hERG in cardiac repolarization and the development of LQTS, it is important to understand the regulation of hERG protein trafficking and expression. The versatile signaling of $G$ protein-coupled receptors (GPCRs) represents a useful route to study hERG regulation (Lee et al., 2001; Takeda et al., 2002). We previously showed that activation of the M3 muscarinic receptor increases hERG channel expression through $\mathrm{G}_{\mathrm{q}}$ protein-mediated activation of protein kinase $\mathrm{C}$ (PKC) (Wang et al., 2014). However, in addition to $\mathrm{G}$ proteins, GPCRs recruit $\beta$-arrestins upon ligand binding (Reiter and Lefkowitz, 2006). $\beta$-Arrestins not only play a crucial role in desensitizing and internalizing GPCRs but they also act as multi-protein scaffolds to promote $\mathrm{G}$ proteinindependent signaling (Luttrell et al., 2001; Ahn et al., 2004; Shenoy et al., 2006; Noma et al., 2007). Traditionally, complex signaling and heterologous expression of GPCRs make it difficult to analyze distinct $\beta$-arrestin signaling pathways (Hermans, 2003). However, the development of designer receptors exclusively activated by designer drugs (DREADDs) has allowed for the selective activation of GPCR subtypes by an otherwise pharmacologically inert ligand (Thiel et al., 2013;

ABBREVIATIONS: Akt, protein kinase B; CCh, carbachol; CNO, clozapine-N-oxide; Ctrl, control; DN, dominant negative; DREADDs, designer receptors exclusively activated by designer drugs; EAG, ether-a-go-go; GAPDH, glyceraldehyde 3-phosphate dehydrogenase; GPCR, G protein-coupled receptor; HA, hemagglutinin; HEK, human embryonic kidney; hERG, human ether-a-go-go-related gene; I $\mathrm{hERG}$, human ether-ago-go-related gene current; $\mathrm{I}_{\mathrm{Kr}}$, rapidly activating delayed rectifier $\mathrm{K}^{+}$current; LQTS, long QT syndrome; M3D-arr, arrestin-biased $\mathrm{M} 3$ muscarinic receptor-based designer receptors exclusively activated by designer drug; PCR, polymerase chain reaction; PI3K, phosphoinositide 3-kinase; PKC, protein kinase C; Ptdlns $(3,4,5) P_{3}$, phosphatidylinositol $(3,4,5)$-trisphosphate; PTEN, phosphatase and tensin homolog deleted on chromosome 10; SGK, serum- and glucocorticoid-inducible kinase. 
Wess et al., 2013). In this regard, the $\beta$-arrestin-biased M3 muscarinic receptor-based DREADD (M3D-arr) represents a powerful tool to examine $\beta$-arrestin signaling. M3D-arr contains two point mutations (Y148C and A238G) that prevent binding of endogenous acetylcholine and allow for activation by the otherwise pharmacologically inert compound, clozapineN-oxide (CNO) (Armbruster et al., 2007; Alvarez-Curto et al., 2011). A third point mutation in the conserved Asp-Arg-Tyr motif, R165L, uncouples $\mathrm{G}_{\mathrm{q}}$ proteins to produce exclusive $\beta$-arrestin signaling upon CNO-induced M3D-arr activation (Nakajima and Wess, 2012).

In the present study, utilizing the M3D-arr, we investigated the role of $\beta$-arrestin in the regulation of hERG channels. We found that CNO-mediated activation of M3D-arr enhanced hERG protein expression and current. Mechanistically, $\beta$-arrestin signaling stimulated phosphoinositide 3-kinase (PI3K)-mediated activation of protein kinase B (Akt), and consequently promoted recycling of hERG channels to the plasma membrane through the phosphatidylinositol 3-phosphate 5-kinase, PIKfyve, and the small GTPase Rab11.

\section{Materials and Methods}

Molecular Biology. The human embryonic kidney (HEK) 293 cell lines that stably express hERG (hERG-HEK cells), Kv1.5 (Kv1.5-HEK cells) or ether-a-go-go (EAG) channels (EAG-HEK cells) were used (Guo et al., 2009, 2012; Lamothe and Zhang, 2013; Wang et al., 2014; Lamothe et al., 2016). hERG cDNA was acquired from Dr. Gail Robertson (University of Wisconsin-Madison, Madison, WI). Kv1.5 cDNA was acquired from Dr. Michael Tamkun (Colorado State University, Fort Collins, CO). hEAG cDNA was acquired from Dr. Luis Pardo (Max-Planck Institute of Experimental Medicine, Göttingen, Germany). The hemaggluttinin (HA)-tagged rat arrestinbiased M3 DREADD [Rq(R165L)] (M3D-arr) plasmid was obtained from Dr. Jürgen Wess (National Institute of Diabetes and Digestive and Kidney Diseases, National Institutes of Health) (Nakajima and Wess, 2012). The FLAG-tagged human phosphatase and tensin homolog deleted on chromosome 10 (PTEN) plasmid was obtained from Dr. Xiaolong Yang (Queen's University). The Rab11 dominantnegative (DN) mutant (Rab11 S25N) plasmid was obtained from Addgene (Cambridge, MA). hERG-HEK cells were maintained in normal culture medium, which contained minimum essential medium (Invitrogen, Burlington, ON, Canada) supplemented with 10\% fetal bovine serum (Invitrogen), $1 \times$ nonessential amino acids, $1 \mathrm{mM}$ sodium pyruvate, and $0.4 \mathrm{mg} / \mathrm{ml} \mathrm{G} 418$ (Invitrogen). Lipofectamine 2000 (Invitrogen) was used to transfect 2 or $8 \mu \mathrm{g}$ of the intended plasmid into HEK cells cultured in 35 or $100 \mathrm{~mm}$ dishes, respectively. Empty pcDNA3 plasmid was used as a control. For electrophysiological studies, cotransfection of a green fluorescent protein plasmid (pIRES2-EGFP, Clontech, Mountain View, CA) with plasmids of interest at a ratio of 1:3 was used to identify transfected cells. Following transfections, cells were cultured for 24 hours before experiments were performed.

Western Blot Analysis. Whole-cell proteins were isolated from HEK cells that express intended proteins after various treatments. Cells were washed twice and collected in ice-cold phosphate-buffered saline. Cells were then suspended in radioimmunoprecipitation assay buffer containing phenylmethylsulfonyl fluoride (1 mM, SigmaAldrich, St. Louis, MO) and a protease inhibitor cocktail (1 $\times$, SigmaAldrich). For detecting phosphorylated Akt, a phosphatase inhibitor PhosSTOP ( $1 \times$, Roche Applied Science, Penzberg, Germany) was added to the buffer solution to stabilize phosphorylated proteins. Whole-cell protein lysates were generated via sonication and centrifugation at $10,000 \mathrm{~g}$ for 10 minutes. Protein concentration measurements were performed using the DC Protein Assay Kit (Bio-Rad,
Hercules, CA). Then, $15 \mu \mathrm{g}$ of protein in $50 \mu \mathrm{l}$ of SDS-PAGE sample buffer was separated using $8 \%$ SDS-polyacrylamide gels. Proteins were then transferred to polyvinylidene difluoride membranes and blocked for 1 hour with 5\% nonfat milk. Membranes were treated with a primary antibody followed by a corresponding horseradish peroxidase-conjugated secondary antibody, each for 1 hour. Incubations were followed by triple 10-minute washes in Tris-buffered saline and $0.1 \%$ Tween 20 . An enhanced chemiluminescent kit (GE Healthcare, Little Chalfont, United Kingdom) was used to visualize proteins on Fuji X-ray films (Fujifilm, Tokyo, Japan). The expression of actin was detected as a control of loading. In each gel, the band intensities of intended proteins were normalized to their corresponding actin intensities. The normalized band intensities of treatment groups were compared with those of controls and expressed as relative values.

Coimmunoprecipitation. For each sample, $0.5 \mathrm{mg}$ of whole-cell protein was incubated with a $\beta$-arrestin- 1 or a $\beta$-arrestin- 2 antibody in $0.5 \mathrm{ml}$ lysis buffer overnight at $4^{\circ} \mathrm{C}$. Glyceraldehyde 3-phosphate dehydrogenase (GAPDH) antibody was used as a negative control. Protein A/G PLUS agarose beads (Santa Cruz Biotechnology, Dallas, TX) was mixed with the protein-antibody complexes for 4 hours at $4^{\circ} \mathrm{C}$. The beads were washed 4 times with $0.5 \mathrm{ml}$ of ice-cold radioimmunoprecipitation assay lysis buffer and centrifuged at 10,000 $\mathrm{g}$ for 2 minutes. After being resuspended in $50 \mu$ l of $2 \times$ Laemmli sample buffer and boiled for 5 minutes, samples were centrifuged at $10,000 \mathrm{~g}$ for 10 minutes. The supernatant was used for Western blot analyses to detect precipitated proteins.

RNA Extraction and Quantitative Reverse Transcription Polymerase Chain Reaction (PCR). Twenty-four hours after transfection of empty pcDNA3 or HA-tagged M3D-arr plasmid into hERG-HEK cells, cells were treated with or without CNO for 24 hours. Total cellular RNA was then extracted from cells using a Total RNA Mini Kit (Geneaid Biotech Ltd., Taiwan), and treated with DNase I (New England BioLabs, Ipswich, MA). RNA concentration was assessed using a spectrophotometer (Spectra MAX Plus; Molecular Devices, Sunnyvale, CA).

Reverse transcription of total RNA ( $1 \mu \mathrm{g})$ to cDNA was performed using the Omniscript reverse transcription kit (Qiagen, Hilden, Germany). Quantitative real-time PCR was performed with TaqMan Gene Expression Master Mix (Life Technologies, Carlsbad, CA) and a thermal cycler (Model 7500; Applied Biosystems, Foster City, CA). GAPDH was used as an internal control (housekeeping) gene. Oligonucleotide primers (hERG: Assay ID, Hs04234270_g1; GAPDH: Assay ID, Hs03929097_g1) were obtained from Life Technologies. The PCR protocol used was as follows: 2 minutes at $50^{\circ} \mathrm{C}$ and 10 minutes at $95^{\circ} \mathrm{C}$, followed by 40 cycles of $95^{\circ} \mathrm{C}$ for 15 seconds and $60^{\circ} \mathrm{C}$ for 1 minute. Data were calculated using the $2^{-\Delta \Delta C \mathrm{~T}}$ method (Livak and Schmittgen, 2001) and expressed as fold induction of hERG normalized to GAPDH.

Immunofluorescence Microscopy. hERG-HEK cells were cultured on glass coverslips and transiently transfected with empty pcDNA3 or HA-tagged M3D-arr plasmid for 24 hours. The cells were then treated without (control, Ctrl) or with CNO. Twentyfour hours after treatment, cells were fixed with an ice-cold $4 \%$ paraformaldehyde/phosphate-buffered saline solution for 15 minutes, permeabilized with $0.1 \%$ Triton $\mathrm{X}-100$ for 10 minutes, and then blocked with $5 \%$ bovine serum albumin for 1 hour. To detect HA-tagged M3D-arr, a rabbit anti-HA primary antibody and an Alexa Fluor 594-conjugated donkey anti-rabbit secondary antibody were used. To detect $\beta$-arrestin- 1 or $\beta$-arrestin- 2 , a goat anti- $\beta$-arrestin- 1 or mouse anti- $\beta$-arrestin- 2 primary antibody and an Alexa Fluor 488conjugated donkey anti-goat or goat anti-mouse secondary antibody was used.

Patch-Clamp Recording. The whole-cell voltage-clamp method was used to record the hERG current $\left(\mathrm{I}_{\mathrm{hERG}}\right), \mathrm{Kv} 1.5$ current, or EAG current in respective stable HEK cells. Cells were held at a holding potential of $-80 \mathrm{mV}$ and elicited by a series of depolarizing steps ranging from -70 to $70 \mathrm{mV}$ in $10 \mathrm{mV}$ increments. The depolarizing steps were followed by repolarizing steps to $-50 \mathrm{mV}$. Current 
amplitudes for $\mathrm{I}_{\mathrm{hERG}}$ were analyzed using peak tail currents after $50 \mathrm{mV}$ depolarizing steps. Current amplitudes for the Kv1.5 current and EAG current were analyzed using currents upon the end of $50-\mathrm{mV}$ depolarizing steps. The bath solution contained $5 \mathrm{mM} \mathrm{KCl}, 135 \mathrm{mM}$ $\mathrm{NaCl}, 2 \mathrm{mM} \mathrm{CaCl}_{2}, 1 \mathrm{mM} \mathrm{MgCl}_{2}, 10 \mathrm{mM}$ glucose, and $10 \mathrm{mM}$ HEPES ( $\mathrm{pH} 7.4$ with $\mathrm{NaOH}$ ). The pipette solution contained $135 \mathrm{mM} \mathrm{KCl}$, $1 \mathrm{mM} \mathrm{MgCl} 2,5 \mathrm{mM}$ EGTA, and $10 \mathrm{mM}$ HEPES (pH 7.2 with $\mathrm{KOH}$ ). Ventricular myocytes were isolated from 1-day-old Sprague-Dawley rats of either sex by enzymatic dissociation (Guo et al., 2007). Cells were cultured in Dulbecco's modified Eagle's medium/Ham's F-12 medium (Invitrogen) supplemented with $10 \%$ fetal bovine serum. Myocytes cultured on coverslips were subjected to various treatments for 24 hours prior to patch-clamp recordings. Then, $\mathrm{I}_{\mathrm{Kr}}$ in neonatal rat ventricular myocytes was isolated using symmetrical $\mathrm{Cs}^{+}$solutions as $\mathrm{Cs}^{+}$-mediated $\mathrm{I}_{\mathrm{Kr}}$. Cells were depolarized to voltages between -70 and $+70 \mathrm{mV}$ in $10 \mathrm{mV}$ increments and repolarized to a holding potential of $-80 \mathrm{mV}$. Peak tail currents upon $-80 \mathrm{mV}$ following depolarizing steps to $50 \mathrm{mV}$ were used to measure $\mathrm{Cs}^{+}$-mediated $\mathrm{I}_{\mathrm{Kr}}$ amplitude (Zhang, 2006).

Reagents and Antibodies. Minimum essential medium, fetal bovine serum, G418, nonessential amino acids, sodium pyruvate, Alexa Fluor 594-conjugated donkey anti-rabbit, and Alexa Fluor 488conjugated donkey anti-goat and goat anti-mouse secondary antibodies were purchased from Invitrogen. Rabbit anti-Kv11.1 (hERG), anti-Kv10.1 (EAG-1), and anti-HA (H6908), mouse anti-FLAG (F3165), anti-HA (H3663), and anti-actin (A4700) primary antibodies, electrolytes, EGTA, HEPES, glucose, bovine serum albumin, Akt1/2 kinase inhibitor (A6730), SC79 (Akt activator, SML0749), and carbamylcholine chloride (carbachol, C4382) were purchased from Sigma-Aldrich. Goat anti-hERG (C-20) (sc-15968), anti- $\beta$-arrestin-1 (sc-9182), anti-GAPDH (sc-20357), mouse anti- $\beta$-arrestin-2 (sc-13140), anti-GAPDH (sc-51907), and rabbit anti-Kv1.5, anti-Akt (sc-1618-R) and anti-p-Akt (sc-135650) primary antibodies, as well as goat anti-mouse (sc-2005), mouse antigoat (sc-2354), goat anti-rabbit (sc-2004) IgG-horseradish peroxidase secondary antibodies, and protein A/G PLUS agarose beads (sc-2003) were purchased from Santa Cruz Biotechnology. YM201636 (PIKfyve inhibitor, 13576) was purchased from Cayman Chemical (Ann Arbor, MI). H7 (PKC inhibitor, I885000) was obtained from Toronto Research Chemicals (North York, ON). PhosSTOP phosphatase inhibitor (04906845001) was purchased from Roche Applied Science (Penzberg, Germany).
Statistical Analysis. All data are presented as the mean \pm S.E.M. In all cases, $n$ indicates the number of independent replicates. Twotailed unpaired Student's $t$ test (Figs. 3 and 7) or ordinary one-way analysis of variance (Fig. 1, 2, 6, and 8-10) was used to determine statistical significance between control and treatment groups. GraphPad Prism (La Jolla, CA) was used for analysis, and Newman-Keuls post hoc tests were used in analysis of variance to determine the differences between control and treatment groups. A $P$-value of less than 0.05 was considered to be statistically significant.

\section{Results}

Activation of M3D-arr Increases Mature hERG Protein Expression and Current. To investigate the effect of M3D-arr activation on hERG, hERG-HEK cells were transfected with empty pcDNA3 (Ctrl) or M3D-arr plasmid. Twenty-four hours following transfection, cells were treated with the selective M3D-arr activator, CNO, at different concentrations and for various time periods. hERG protein expression was analyzed using Western blot analysis.

On Western blots, hERG proteins display two bands with molecular masses of 135 and $155 \mathrm{kDa}$. It has been established that under normal culture conditions, the $135-\mathrm{kDa}$ band represents the immature, core-glycosylated channel proteins localized in the endoplasmic reticulum, and the $155-\mathrm{kDa}$ band represents the mature, fully glycosylated channel proteins localized in the plasma membrane (Zhou et al., 1998; Gong et al., 2002). The distinct cellular localization of the immature $(135-\mathrm{kDa})$ and mature $(155-\mathrm{kDa}) \mathrm{hERG}$ proteins has been consistently demonstrated by a series of previous works. For example, biotinylation-isolated cell-surface proteins from hERG-HEK cells only display the 155-kDa hERG band (Gianulis and Trudeau, 2011; Kang et al., 2015). Also, selective cleavage of cell-surface proteins using extracellularly applied proteinase $\mathrm{K}$ completely eliminates the 155kDa hERG band but does not affect the 135-kDa hERG band (Zhou et al., 1998; Rajamani et al., 2006; Lamothe et al., 2016). Furthermore, inhibition of hERG maturation by blocking
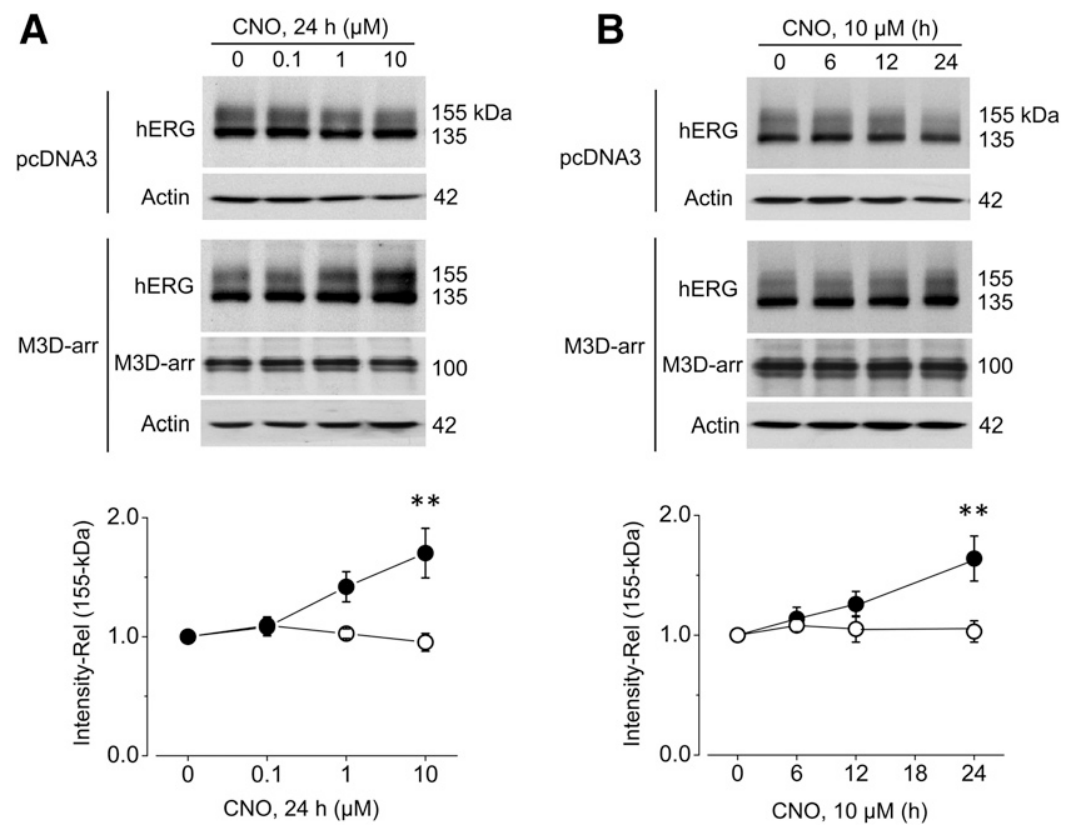

Fig. 1. Activation of $\beta$-arrestin-biased M3D-arr by $\mathrm{CNO}$ increases mature hERG expression levels in a concentrationand time-dependent manner. (A) Concentration-dependent effect of CNO on hERG expression $(n=4)$. (B) Time-dependent effect of $10 \mu \mathrm{M}$ CNO on hERG expression $(n=3)$. In both (A) and (B), hERG-HEK cells were transfected with empty pcDNA3 (Ctrl, O) or HA-tagged M3D-arr plasmid (๑). Twentyfour hours after transfection, cells were treated with CNO under various conditions. Whole-cell lysates were collected for Western blot analysis. In each gel, band intensities of the 155 -kDa hERG proteins with CNO treatments were normalized to the control and expressed as relative values. Summarized data are presented in the graphs beneath the Western blots. ${ }^{* *} P<0.01$ versus control $(0 \mu \mathrm{M}$ and 0 hour, respectively). 
protein Golgi transit using brefeldin A completely eliminates the $155-\mathrm{kDa}$ hERG band as well as the presence of hERG in the plasma membrane (Guo et al., 2009). Thus, we take advantage of the two separate bands to investigate the effects of M3D-arr activation on the mature and immature hERG protein expression. Treatment with $0.1,1$, and $10 \mu \mathrm{M}$ CNO increased mature hERG expression in M3D-arr-transfected cells (but not in pcDNA3-transfected cells) in a concentrationdependent manner (Fig. 1A). Furthermore, treatment of cells with $10 \mu \mathrm{M}$ CNO caused a time-dependent increase in mature hERG expression (Fig. 1B). CNO is inert in hERG-HEK cells without M3D-arr; treatment of pcDNA3-transfected cells with $10 \mu \mathrm{M}$ CNO for 24 hours had no effect on hERG expression (Fig. 1).

M3D-arr expression alone did not affect hERG expression (Fig. 2A). CNO significantly enhanced the expression of the $155-\mathrm{kDa}$ (but not the $135-\mathrm{kDa}$ ) hERG protein in M3D-arrtransfected hERG-HEK cells (Fig. 2A). Quantitative reverse transcription PCR on pcDNA3- and M3D-arr-transfected hERG-HEK cells cultured without (Ctrl) or with CNO was performed. CNO did not alter the relative hERG mRNA expression levels in pcDNA3- or M3D-arr-transfected hERGHEK cells (Fig. 2B). To record $\mathrm{I}_{\text {hERG, }}$, whole-cell patch-clamp experiments were conducted. Families of $\mathrm{I}_{\mathrm{hERG}}$ were recorded with the protocol shown in the inset in Fig. 2C. The activationvoltage relationship of hERG channels was obtained by fitting the tail current-depolarizing voltage relationships to the Hill equation. In pcDNA3-transfected hERG-HEK cells, the halfactivation voltage and the slope factor were $-1.7 \pm 2.5 \mathrm{mV}$ and $7.9 \pm 0.4$ in control cells $(n=11)$ and $-5.2 \pm 2.5 \mathrm{mV}$ and $8.1 \pm$ 0.6 in CNO-treated cells ( $n=7, P>0.05)$. Thus, CNO was inert in the absence of M3D-arr and did not affect $\mathrm{I}_{\mathrm{hERG}}$. However, CNO significantly increased $\mathrm{I}_{\mathrm{hERG}}$ in M3D-arr-transfected cells without affecting the activation-voltage relationship of hERG channels (Fig. 2D). In M3D-arr-transfected hERG-HEK cells, the half-activation voltage and the slope factor were $-4.0 \pm$ $2.8 \mathrm{mV}$ and $7.3 \pm 0.3$ in control cells $(n=10)$ and $-0.5 \pm$ $2.7 \mathrm{mV}$ and $7.5 \pm 0.2$ for CNO-treated cells $(n=12, P>0.05)$.

The hERG channel displays various unique properties. With regard to protein trafficking, we have previously shown that the ubiquitin ligase Nedd4-2 targeting motif PPxY exists in hERG but not in Kv1.5 or EAG (Guo et al., 2012). Also, we have shown that activation of the serum- and glucocorticoidinducible kinase (SGK) enhances hERG, but not Kv1.5 or EAG, expression via Nedd4-2 and GTPase Rab11-mediated recycling (Lamothe and Zhang, 2013). To test the specificity of M3D-arr activation on potassium channels, HEK cells stably expressing Kv1.5 or EAG channels were transfected with M3D-arr plasmid. Then, 24 hours after transfection cells were treated without $(\mathrm{Ctrl})$ or with CNO $(10 \mu \mathrm{M})$. CNO treatment did not affect the expression or function of either Kv1.5 or EAG channels (Fig. 3).
A
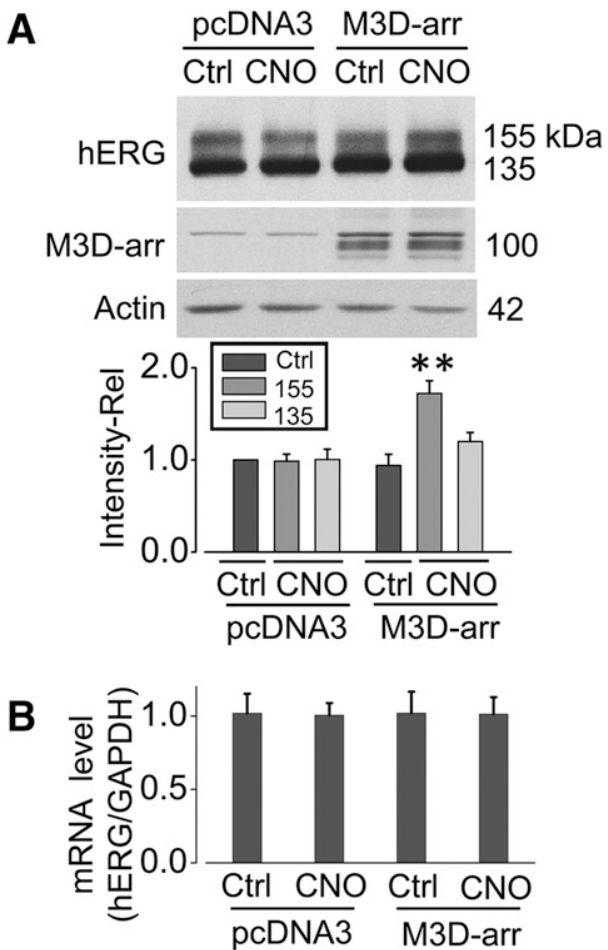

C
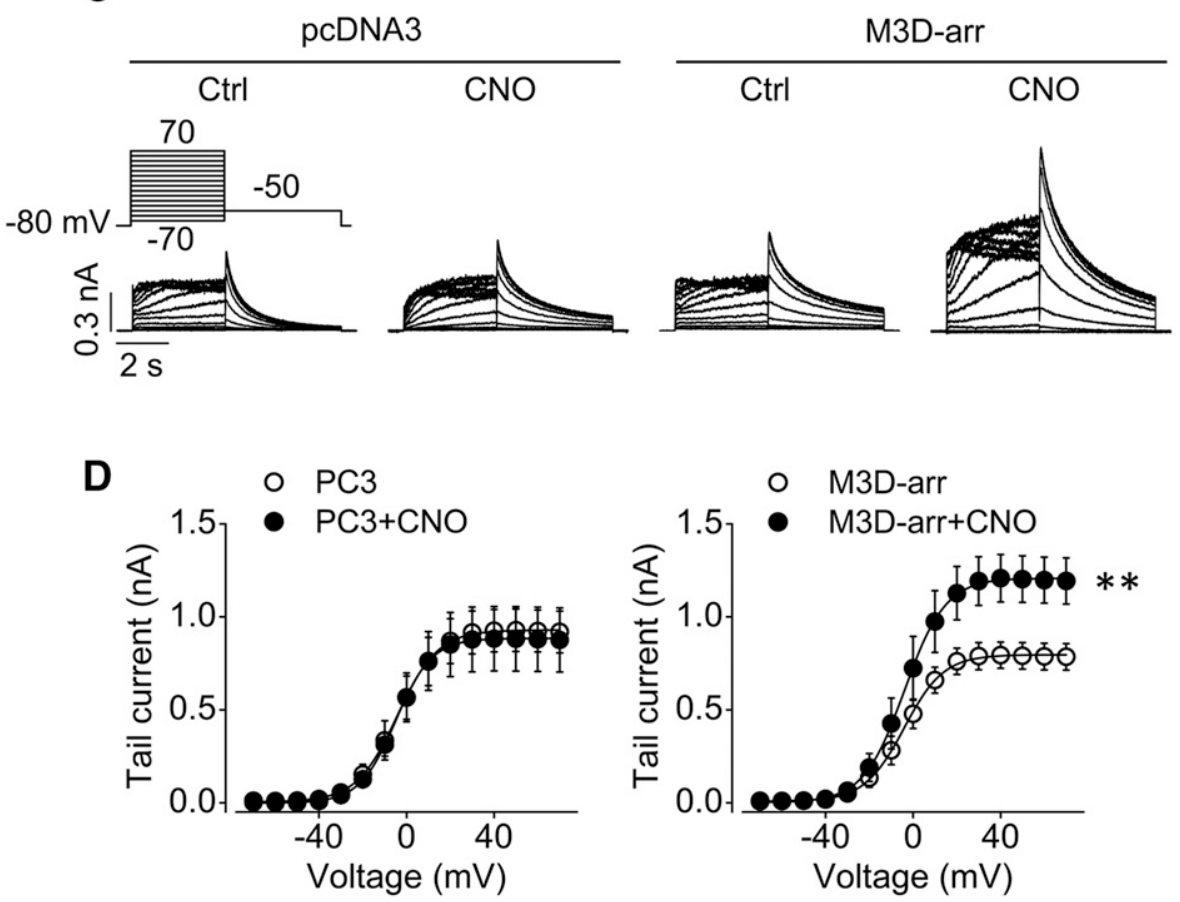

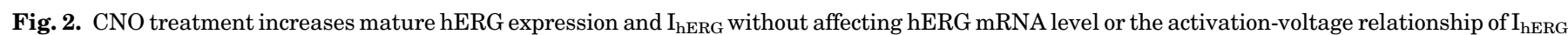

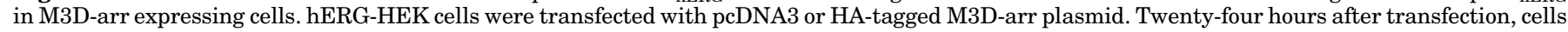

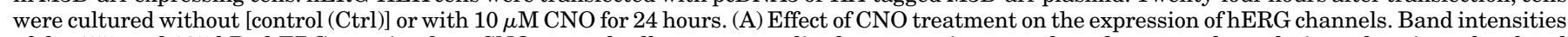

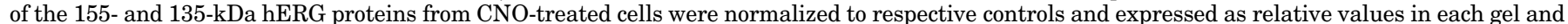

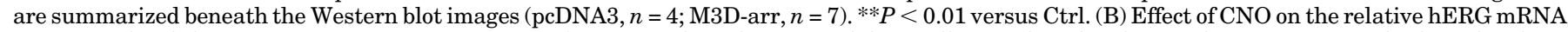

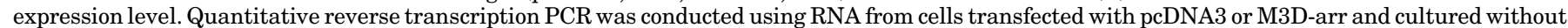

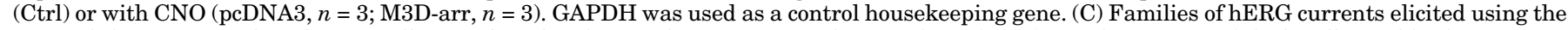

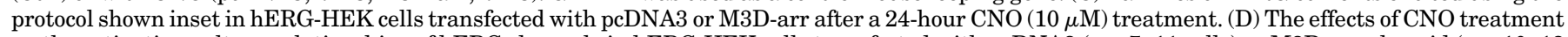

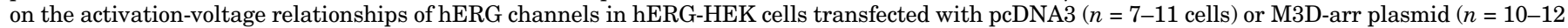
cells from four independent trials). ${ }^{*} P<0.01$ versus $\mathrm{Ctrl}$ for the maximal tail currents. 


\begin{tabular}{cc}
\multicolumn{2}{c}{ M3D-arr } \\
\hline Kv1.5 & EAG \\
\hline
\end{tabular}

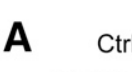

CNO
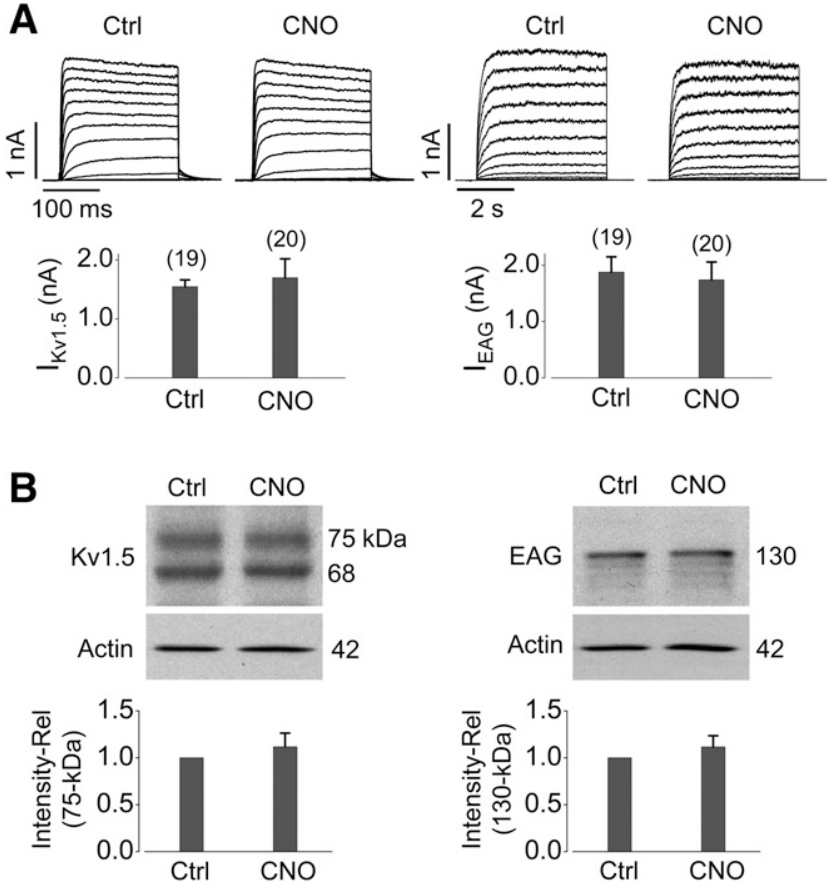

Fig. 3. CNO treatment affects neither Kv1.5 nor EAG channels in M3Darr expressing cells. (A) Representative Kv1.5 current $\left(\mathrm{I}_{\mathrm{Kv} .5}\right)$ or EAG current $\left(\mathrm{I}_{\mathrm{EAG}}\right)$ in respective stable HEK cells transfected with M3D-arr with or without 24-hour CNO $(10 \mu \mathrm{M})$ treatment. Summarized current amplitudes are shown below the traces. The numbers above the bar graphs indicate the number of cells examined from four independent experiments. (B). Effects of CNO on the expression of Kv1.5 and EAG channel proteins. The relative band intensities of channel proteins in cells treated with CNO are normalized to control and shown beneath the representative Western blot images ( $n=4$ for Kv1.5, and $n=4$ for EAG).

CNO Enhances M3D-arr/ $\beta$-Arrestin Interaction and Colocalization at the Plasma Membrane. Among four arrestin isoforms, $\beta$-arrestin-1 (arrestin 2) and $\beta$-arrestin-2 (arrestin 3) exhibit 78\% amino acid sequence homology and are ubiquitously expressed in various tissues (Attramadal et al., 1992; Sterne-Marr et al., 1993). Following agonist binding, $\beta$-arrestins associate with GPCRs to facilitate receptor desensitization and internalization, as well as $\mathrm{G}$ protein-independent signaling (Goodman et al., 1996; Shenoy et al., 2006). $\beta$-Arrestin recruitment is common to many GPCRs, including the $\beta_{2}$-adrenergic receptor, angiotensin II type 1 receptor, muscarinic M2 receptor, and muscarinic M3 receptor (Pals-Rylaarsdam et al., 1997; Ahn et al., 2004; Novi et al., 2005; Shenoy et al., 2006). M3D-arr is designed to recruit $\beta$-arrestins upon CNO binding (Nakajima and Wess, 2012; Wess et al., 2013; Wess, 2016). Since $\beta$-arrestin isoforms display varying affinity for different GPCRs (Oakley et al., 2000), we investigated whether $\beta$-arrestin- $1, \beta$-arrestin- 2 , or both interact with M3D-arr upon CNO treatment. To this end, coimmunoprecipitation experiments were performed on hERG-HEK cells transfected with M3D-arr and cultured without (Ctrl) or with CNO for 24 hours. Specific anti$\beta$-arrestin antibodies were used to immunoprecipitate either $\beta$-arrestin-1 or $\beta$-arrestin- 2 and its associated proteins from whole-cell lysates. Precipitates were then immunoblotted with an anti-HA antibody to detect for M3D-arr. As shown in Fig. 4, CNO treatment significantly increased the interaction between M3D-arr and $\beta$-arrestin-1, but not $\beta$-arrestin-2 .

To visualize the M3D-arr/ $\beta$-arrestin interaction, immunocytochemical analysis was performed on hERG-HEK cells transfected with M3D-arr and cultured without (Ctrl) or with CNO for 24 hours. After permeabilization, cells were probed with anti- $\beta$-arrestin- 1 or anti- $\beta$-arrestin- 2 and anti-HA (to detect M3D-arr) primary antibodies. Corresponding Alexa Fluor 594- and Alexa Fluor 488-conjugated secondary antibodies were then used to visualize M3D-arr and $\beta$-arrestin- 1 or $\beta$-arrestin- 2 , respectively. As shown in confocal images in Fig. 5 , there was increased colocalization between $\beta$-arrestin- 1 and M3D-arr at the plasma membrane following CNO treatment (Fig. 5A). However, there was no increase in colocalization between $\beta$-arrestin- 2 and M3D-arr at the plasma membrane following CNO treatment (Fig. 5B). These data are consistent with the coimmunoprecipitation results, and indicate that M3D-arr activation via CNO enhances the interaction between M3D-arr and $\beta$-arrestin- 1 at the plasma membrane.

Activation of M3D-arr Increases hERG Expression through an Akt-Dependent Pathway. Muscarinic M3 receptors couple with $G_{q}$ proteins to activate phospholipase C, which cleaves phosphatidylinositol 4,5-bisphosphate to produce inositol 1,4,5-trisphosphate and diacylglycerol (Eglen, 2012). Inositol 1,4,5-trisphosphate stimulates the

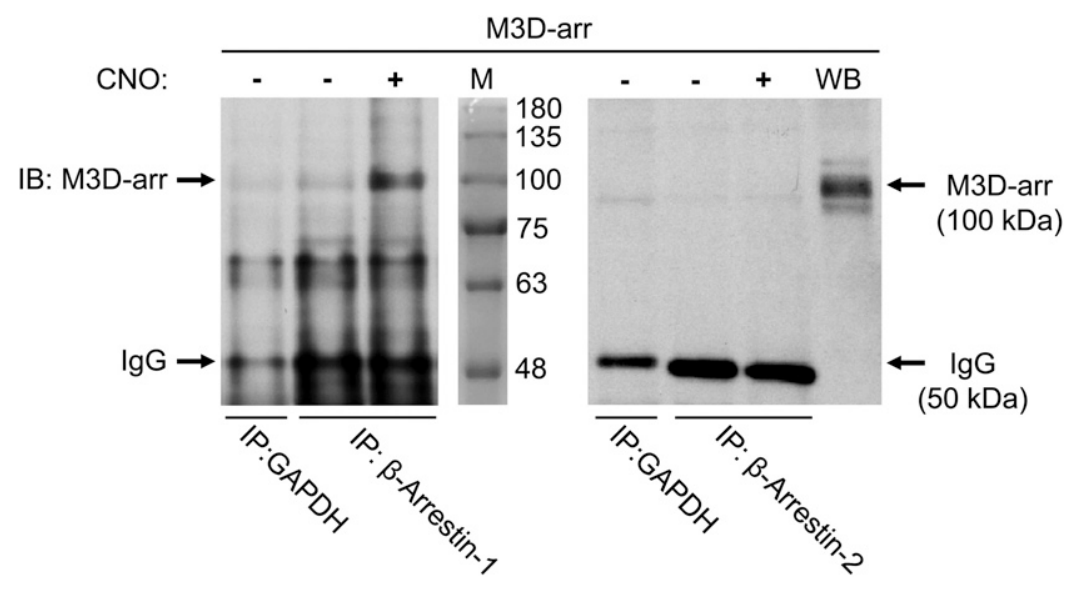

Fig. 4. CNO treatment enhances the interaction between M3D-arr and $\beta$-arrestin-1. Coimmunoprecipitation experiments illustrating that $\mathrm{CNO}$ treatment intensifies the interaction between M3D-arr and $\beta$-arrestin- 1 (left) but not between M3D-arr and $\beta$-arrestin-2 (right). pcDNA3 or HA-tagged M3D-arr transfected hERG-HEK cells were treated with $10 \mu \mathrm{M}$ CNO for 24 hours. Whole-cell lysates were immunoprecipitated with a goat anti- $\beta$-arrestin- 1 or mouse anti- $\beta$-arrestin- 2 antibody. HA-tagged M3D-arr was detected in the immunoprecipitates using an anti-HA primary and appropriate secondary antibodies. Anti-GAPDH was used as a negative control. The difference in background noise between the two panels is due to the different species of antibodies used for immunoprecipitations. $M$ denotes molecular weight marker. WB denotes a Western blot of M3D-arr expression. Similar data were obtained in five independent experiments. 
A

A DIC
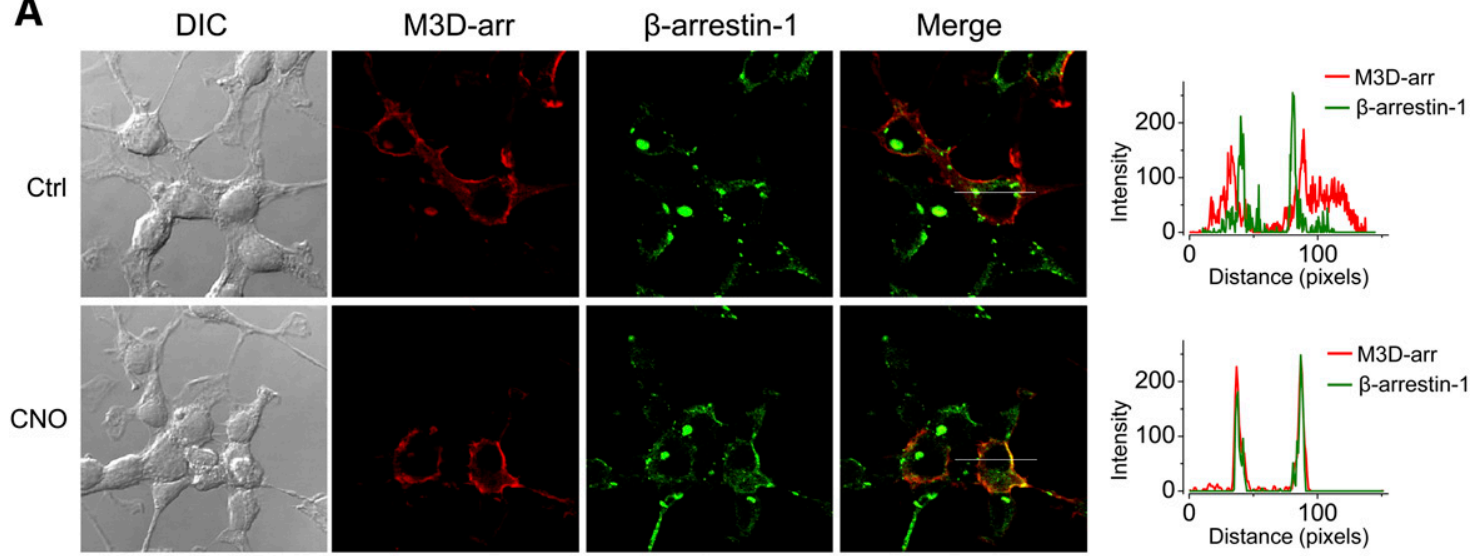

B
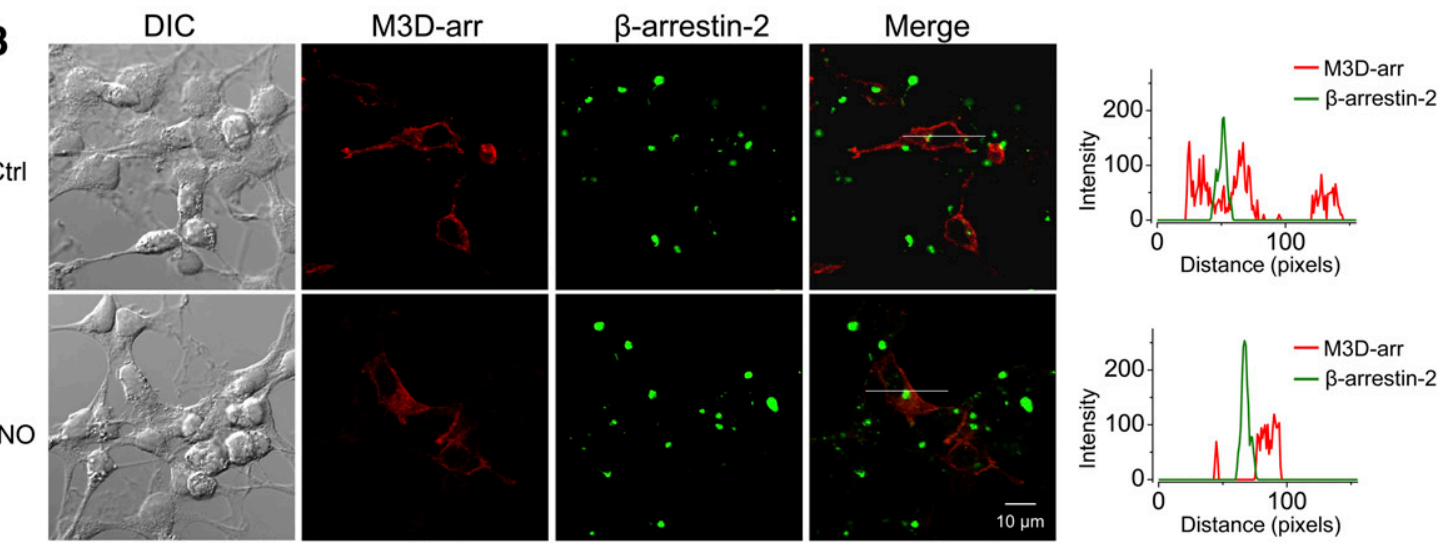

Fig. 5. CNO enhances the $\beta$-arrestin-1/M3D-arr interaction. Confocal images showing that CNO treatment intensifies the interaction between $\beta$-arrestin-1 and M3D-arr (A), but not the interaction between $\beta$-arrestin-2 and M3D-arr (B), at the plasma membrane. HA-tagged M3D-arr-transfected hERG-HEK cells grown on glass coverslips were cultured without [control (Ctrl)] or with $10 \mu \mathrm{M}$ CNO for 24 hours. Cells were fixed and permeabilized. M3D-arr was labeled with a rabbit anti-HA primary antibody and an Alexa Fluor 594-conjugated donkey anti-rabbit secondary antibody. $\beta$-Arrestin-1 or $\beta$-arrestin-2 was labeled with a goat anti- $\beta$-arrestin- 1 or mouse anti- $\beta$-arrestin-2 primary antibody and an Alexa Fluor 488 -conjugated donkey anti-goat or goat anti-mouse secondary antibody. Cells are shown in differential interference contrast (DIC) images on the left. Intensities of the fluorescence signals of the lines across the representative cells in each condition are quantified by ImageJ and shown in the right panels. Similar data were obtained in four independent experiments.

release of $\mathrm{Ca}^{2+}$ from the endoplasmic reticulum whereas diacylglycerol activates PKC. We recently reported that activation of the $\mathrm{M} 3$ receptor via carbachol $(\mathrm{CCh})$ increases hERG expression through a PKC-dependent pathway (Wang et al., 2014). However, M3D-arr contains a point mutation (R165L) that disrupts the $\mathrm{G}_{\mathrm{q}}$ protein-coupled PKC pathway (Nakajima and Wess, 2012). To verify that activation of M3D-arr increases mature hERG expression through a
A
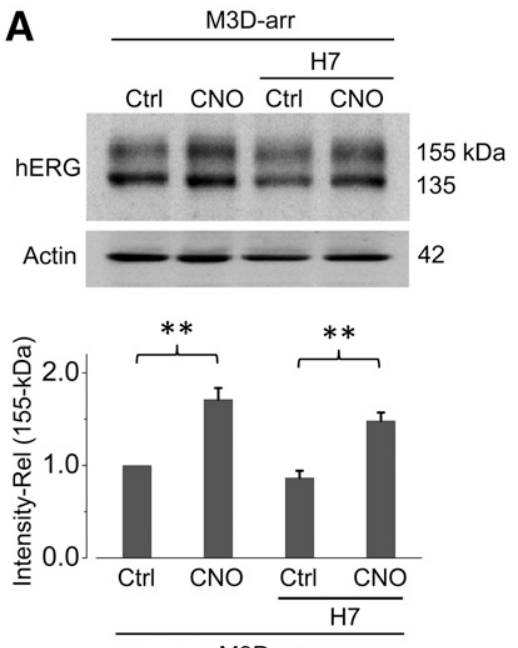

M3D-arr
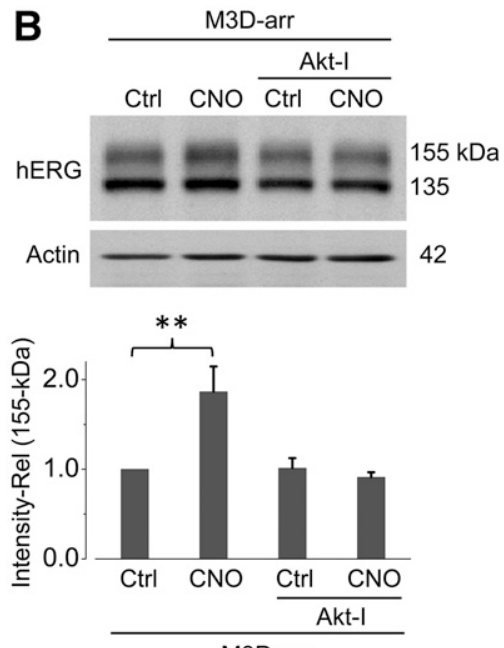

Fig. 6. CNO treatment increases hERG expression through a PKC-independent but Akt-dependent pathway in M3D-arr-transfected hERG-HEK cells. (A) PKC inhibition does not affect the CNO-induced increase in hERG expression. M3D-arr-transfected hERG-HEK cells were cultured without [control (Ctrl)] or with $10 \mu \mathrm{M}$ CNO for 24 hours in the absence or presence of $50 \mu \mathrm{M}$ of $\mathrm{H} 7$, a PKC inhibitor $(n=9)$. (B) Akt inhibition abolishes the CNOinduced increase in hERG expression. M3D-arr-transfected hERG-HEK cells were cultured without (Ctrl) or with $10 \mu \mathrm{M}$ CNO for 24 hours in the absence or presence of $2.5 \mu \mathrm{M}$ of Akt-I $(n=6)$. Whole-cell lysates were extracted and assessed using Western blot analysis. Band intensities of the $155-\mathrm{kDa}$ hERG were normalized to the controls and expressed as relative values in each gel and are summarized beneath the Western blot images. ${ }^{*} * P<0.01$ versus $\mathrm{Ctrl}$. 
PKC-independent pathway, M3D-arr-transfected hERGHEK cells were cultured without $(\mathrm{Ctrl})$ or with $\mathrm{CNO}$ in the absence or presence of the PKC inhibitor, H7 $(50 \mu \mathrm{M})$. After PKC inhibition, increased mature hERG expression induced by CNO-mediated M3D-arr activation was still present (Fig. $6 \mathrm{~A}$ ), indicating the involvement of a $\mathrm{G}_{\mathrm{q}}$ protein-independent pathway.

In addition to $G_{q}$ proteins, stimulation of muscarinic M3 receptors promotes the activation of PI3K and Akt (Guizzetti and Costa, 2001). $\beta$-Arrestin-1 has been shown to mediate PI3K/Akt signaling (Povsic et al., 2003). It has also been reported that $\mathrm{PI} 3 \mathrm{~K}$-dependent activation of Akt increases hERG channel function in hERG-expressing HEK293 cells (Zhang et al., 2003). We hypothesized that M3D-arr activation and subsequent recruitment of $\beta$-arrestin- 1 enhances Akt activation, leading to increased mature hERG expression. We performed three sets of experiments to assess our hypothesis. First, we examined the effects of Akt inhibition on the increase mediated by M3D-arr activation. We cultured M3D-arrtransfected hERG-HEK cells without (Ctrl) or with CNO in the absence or presence of an Akt kinase inhibitor (Akt-I, 2.5 $\mu \mathrm{M})$. As shown in Fig. 6B, inhibition of Akt abolished the CNO-induced increase in mature hERG expression. Second, we assessed total (nonphosphorylated and phosphorylated) Akt and active (phosphorylated) Akt expression in M3Darr-transfected hERG-HEK cells upon CNO treatment. As shown in Fig. 7A, CNO treatment significantly increased the expression level of phosphorylated Akt (but not total Akt) in conjunction with increased mature hERG expression. Third, we cultured hERG-HEK cells with the Akt activator, SC79 $(12 \mu \mathrm{M})$ to address the causative role of Akt activation in the increased mature hERG expression. SC79 significantly increased the expression level of phosphorylated Akt and mature hERG expression in hERG-HEK cells (Fig. 7B). SC79 treatment also significantly increased $\mathrm{I}_{\mathrm{hERG}}$ (Fig. 7C).

As a phospholipid kinase, PI3K phosphorylates phosphatidylinositol 4,5-bisphosphate to produce phosphatidylinositol $(3,4,5)$-trisphosphate $\left[\operatorname{Ptd} \operatorname{Ins}(3,4,5) P_{3}\right]$ at the plasma membrane. Generation of $\operatorname{PtdIns}(3,4,5) P_{3}$ promotes membrane localization and activation of downstream effectors containing a pleckstrin homology domain such as phosphoinositidedependent kinase-1, leading to the activation of Akt (Alessi et al., 1997; Stephens et al., 1998; Milburn et al., 2003). It has been established that PI3K-dependent activation of Akt is antagonized by the phosphatidylinositol 3'-phosphatase PTEN (Oudit et al., 2004; Oudit and Penninger, 2009). We overexpressed PTEN in M3D-arr-transfected hERG-HEK cells and examined the effect of CNO treatment on the expression of Akt, as well as hERG expression and $\mathrm{I}_{\mathrm{hERG}}$. Western blot analyses showed that PTEN overexpression abolished the CNO-induced increase in phosphorylated Akt and mature hERG expression (Fig. 8A). Electrophysiological data showed that PTEN overexpression also eliminated the CNO-induced increase in $\mathrm{I}_{\mathrm{hERG}}($ Fig. 8B).
A
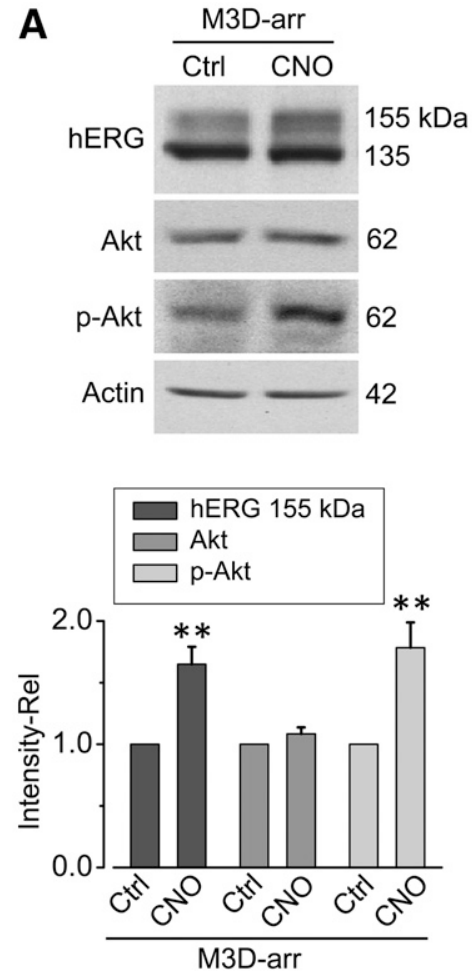

B
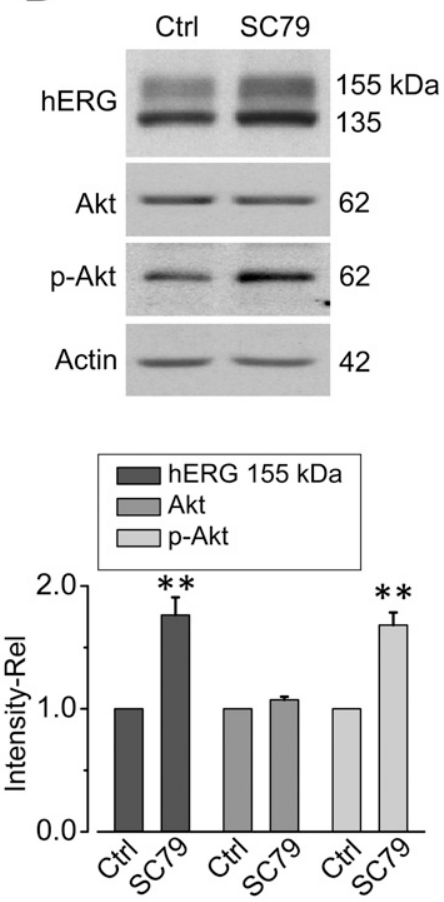

C

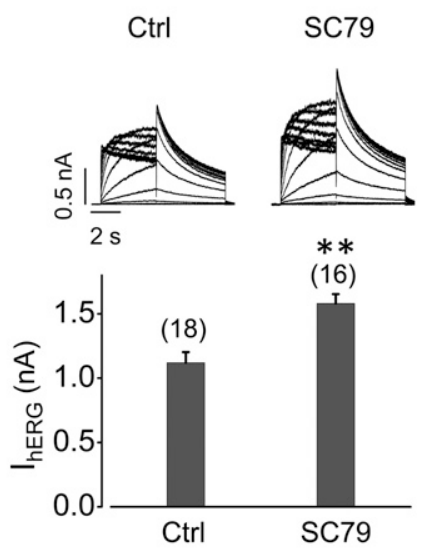

Fig. 7. CNO-mediated M3D-arr activation increases the expression level of hERG as well as phosphorylated Akt (p-Akt). (A) Effect of CNO on hERG, total Akt, and p-Akt in M3D-arr-transfected hERG-HEK cells. Whole-cell lysates were collected 24 hours after culture without [control (Ctrl)] or with $10 \mu \mathrm{M}$ CNO $(n=5-10)$. (B) Effect of Akt activator, SC79, on hERG, total Akt, and p-Akt expression in hERG-HEK cells. Whole-cell lysates were extracted from cells treated with dimethylsulfoxide (DMSO) (Ctrl) or $12 \mu \mathrm{M} \mathrm{SC79}(n=7)$. In (A) and (B), band intensities of the 155-kDa hERG, Akt, and p-Akt in CNO- or SC79-treated cells were normalized to their respective controls and expressed as relative values in each gel and are summarized beneath the Western blot images. (C) Effect of SC79 on $\mathrm{I}_{\mathrm{hERG}}$. Summarized $\mathrm{I}_{\mathrm{hERG}}$ amplitudes are shown beneath the representative families of $\mathrm{I}_{\mathrm{hERG}}$ from cells treated with DMSO (Ctrl) or SC79. The numbers above the bar graphs indicate the number of cells examined from four independent experiments. $* * P<0.01$ versus Ctrl. 
A

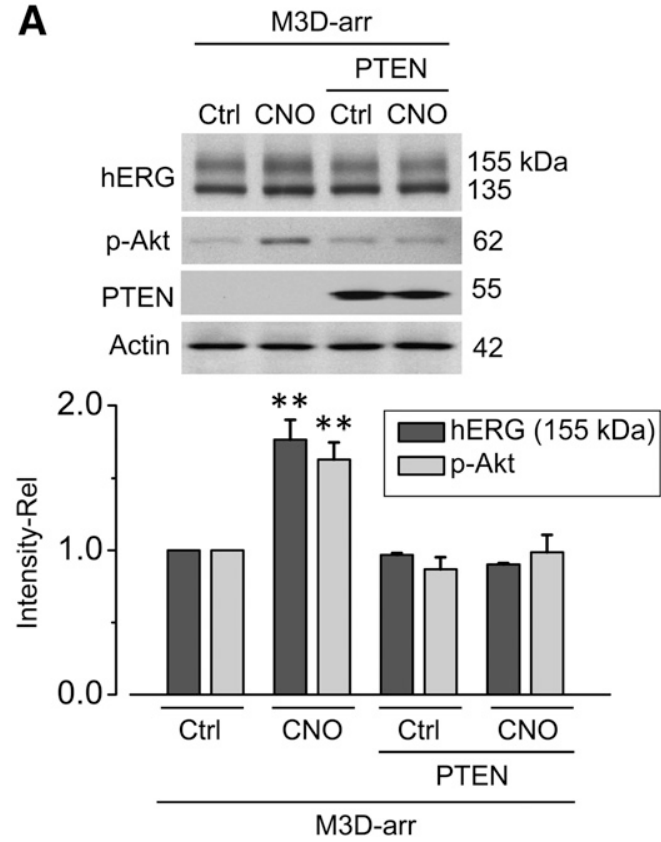

B
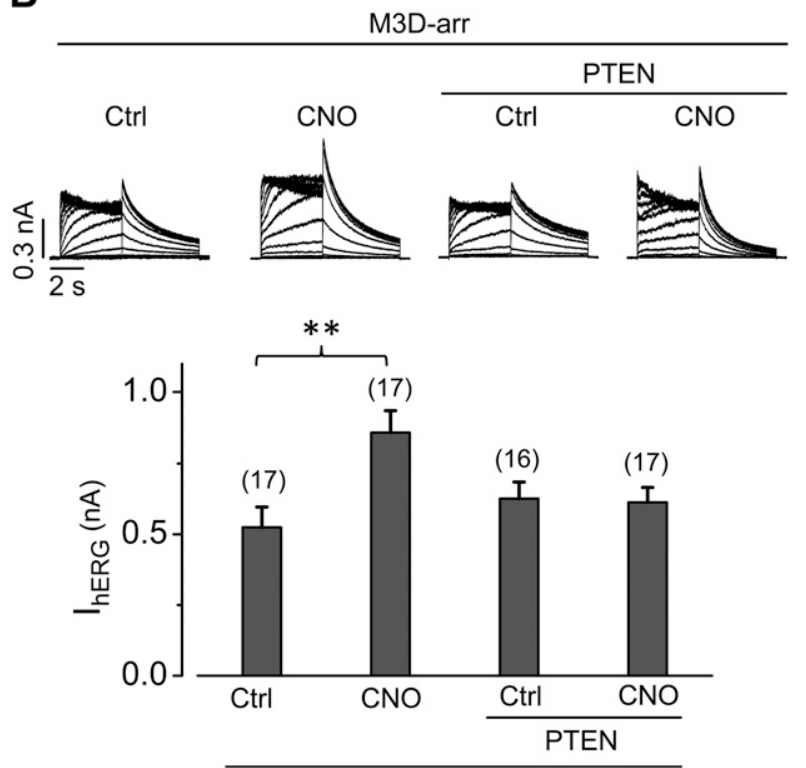

M3D-arr

Fig. 8. CNO treatment increases mature hERG expression and $\mathrm{I}_{\mathrm{hERG}}$ through PI3K-mediated activation of Akt in M3D-arr-transfected hERG-HEK cells. M3D-arr-transfected hERG-HEK cells were additionally transfected without or with the PI3K inhibitor, PTEN. Cells were then cultured without [control (Ctrl)] or with $10 \mu \mathrm{M}$ CNO for 24 hours. PTEN blocks the CNO-induced increase in mature hERG and phosphorylated Akt (p-Akt) expression (A) and $\mathrm{I}_{\mathrm{hERG}}(\mathrm{B})$. For Western blot analysis, band intensities of the 155-kDa hERG and p-Akt from CNO-treated cells were normalized to their respective controls and expressed as relative values in each gel and are summarized beneath the Western blot images $(n=6)$. For whole-cell patch clamp, summarized $\mathrm{I}_{\mathrm{hERG}}$ is shown beneath the representative families of $\mathrm{I}_{\mathrm{hERG}}$ in each condition. The numbers above the bar graphs indicate the number of cells examined from three independent experiments. ${ }^{*} P P<0.01$ versus $C$ trl.

Inhibition of PIKfyve or Rab11 Abolishes the Effect of M3D-arr Activation on $\mathbf{I}_{\mathbf{h E R G}}$. A downstream target of Akt, phosphatidylinositol-3-phosphate-5-kinase (PIKfyve), promotes endosomal trafficking of transmembrane proteins such as hERG and KCNQ1 channels, as well as GLUT4 carriers to the cell surface (Berwick et al., 2004; Seebohm et al., 2007; Pakladok et al., 2013). Upon phosphorylation by Akt, PIKfyve phosphorylates phosphatidylinositol 3-phosphate to produce phosphatidylinositol 3,5-bisphosphate, a phospholipid implicated in the stability of intracellular vesicles (McEwen et al., 1999; de Lartigue et al., 2009). To evaluate the role of PIKfyve in the CNO-mediated increase in $\mathrm{I}_{\mathrm{hERG}}$, we studied the effects of the PIKfyve inhibitor, YM201636, on the CNOmediated increase of $\mathrm{I}_{\mathrm{hERG}}$ in M3D-arr-transfected hERGHEK cells. Inhibition of PIKfyve abolished the CNO-induced increase in $\mathrm{I}_{\mathrm{hERG}}$ (Fig. 9).

We previously demonstrated that the small GTPase Rab11 is involved in hERG channel recycling (Lamothe and Zhang,

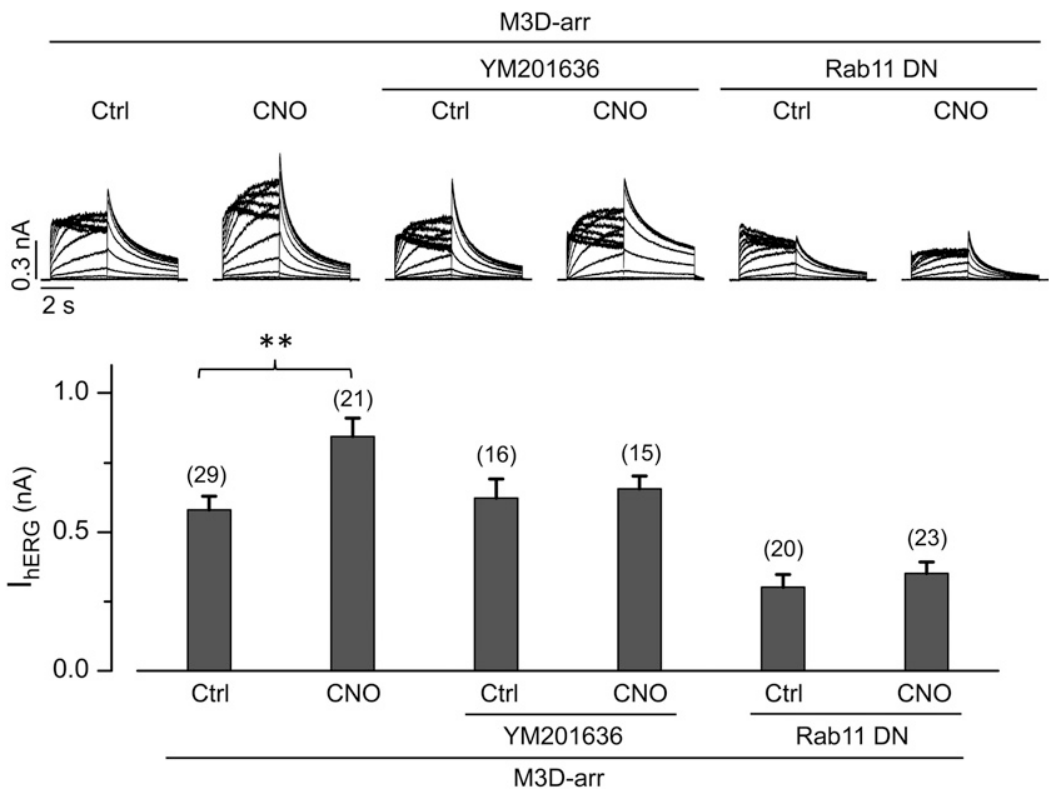

Fig. 9. The CNO-mediated increase in $I_{h E R G}$ is abolished by inhibition of PIKfyve or Rab11 in M3D-arr-transfected hERG-HEK cells. hERG-HEK cells were transfected with M3D-arr alone or together with Rab11 DN mutant S25N. Twenty-four hours after transfection, cells were treated with CNO (10 $\mu \mathrm{M}, 24$ hours) in the absence or presence of PIKfyve inhibitor, YM201636 (0.2 $\mu \mathrm{M}$, in M3D-arr-transfected cells). Cells were then collected for $\mathrm{I}_{\text {hERG }}$ recordings. The summarized $\mathrm{I}_{\mathrm{hERG}}$ amplitudes are shown beneath the representative families of $\mathrm{I}_{\mathrm{hERG}}$ in each condition. The numbers above the bar graphs indicate the number of cells examined from 3 to 5 independent experiments. ${ }^{*} P<0.01$ versus control (Ctrl). 
2013; Chen et al., 2015). It was also reported that stimulation of PIKfyve enhances Rab11-mediated transport of KCNQ1/KCNE1 channels to the membrane (Seebohm et al., 2007). To examine the role of Rab11 in the CNO-mediated increase in $\mathrm{I}_{\mathrm{hERG}}$, we interfered with Rab11 function by overexpressing a Rab11 DN mutant (Rab11 S25N) in M3Darr-transfected hERG-HEK cells and examined the effect of CNO on $\mathrm{I}_{\mathrm{hERG}}$. Overexpression of Rab11 DN reduced $\mathrm{I}_{\mathrm{hERG}}$ in control cells, indicating that Rab11-contributed hERG homeostasis had been disrupted (Chen et al., 2015). Moreover, overexpression of the Rab11 DN mutant abolished the CNOinduced increase in $\mathrm{I}_{\mathrm{hERG}}$ (Fig. 9).

We used CNO to activate M3D-arr to generate $\beta$-arrestin signaling in the present study. Using wild-type and mutant M3 receptors, Alvarez-Curto et al. (2011) concluded that there is no functional selectivity associated with $\mathrm{CNO}$, and activation of M3-DREADDs by CNO produces responses very similar to activation of wild-type M3 receptors by acetylcholine. To demonstrate whether activation of native M3 receptors enhances hERG expression via $\beta$-arrestin signaling, we stimulated endogenous M3 using CCh $(50 \mu \mathrm{M})$ in hERG-HEK cells in the presence of $\mathrm{H} 7$ which blocks $\mathrm{G}_{\mathrm{q}}$ protein-mediated PKC activation. Our data show that although $\mathrm{H} 7$ blocked the CCh-induced increase in mature hERG expression following an 8-hour treatment (Wang et al., 2014), it could not block the CCh-induced increase in mature hERG expression and $\mathrm{I}_{\mathrm{hERG}}$ following a 24-hour treatment (Fig. 10, A and B). Furthermore, the 24-hour CCh-mediated hERG increase was eliminated by the Akt inhibitor, Akt-I (Fig. 10, A and B).

To investigate whether $\beta$-arrestin-mediated hERG regulation occurs in cardiac myocytes we examined the effects of CCh on $\mathrm{I}_{\mathrm{Kr}}$ in neonatal rat ventricular myocytes in the presence of $\mathrm{H} 7$ to block PKC activation. Similar to the results obtained in hERG-HEK cells, a 24-hour treatment with CCh increased $\mathrm{I}_{\mathrm{Kr}}$ in ventricular myocytes in the presence of $\mathrm{H} 7$, and the effect was abolished by Akt-I (Fig. 10C).

\section{Discussion}

hERG $\mathrm{K}^{+}$channels are critical for the repolarization of the cardiac action potential and dysregulation of hERG channel expression or function underlies prolonged QT intervals under various pathologic conditions (Keating and Sanguinetti, 2001). Blockade of hERG channel activity by the off-target actions of many therapeutic agents has been a major area of investigation and rationale for screening compounds during drug development to exclude long QT risks (Roden, 2004; Shah, 2005). Studies from our laboratory and others have indicated that aberrant hERG trafficking to the plasma membrane can also contribute to LQTS effects of some drugs (Dennis et al., 2007; Guo et al., 2007). Thus, understanding the basic cell physiology of hERG channel trafficking and its regulation by various receptor-mediated signaling pathways is important. We previously demonstrated that activation of M3 muscarinic receptors increases hERG channel expression by inhibiting the ubiquitin ligase Nedd4-2 through $\mathrm{G}_{\mathrm{q}}$ proteindependent activation of PKC (Wang et al., 2014). Upon activation, M3 receptors also recruit $\beta$-arrestins to scaffold $\mathrm{G}_{\mathrm{q}}$ protein-independent signaling (Novi et al., 2005). However, the role of $\beta$-arrestin signaling in hERG regulation has not been addressed.
A

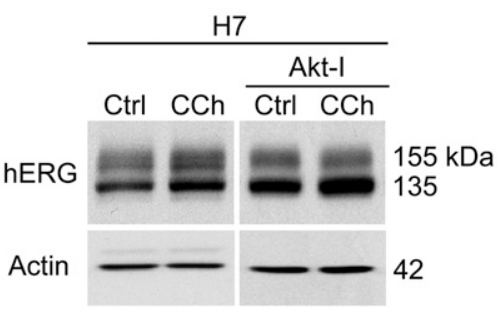

B

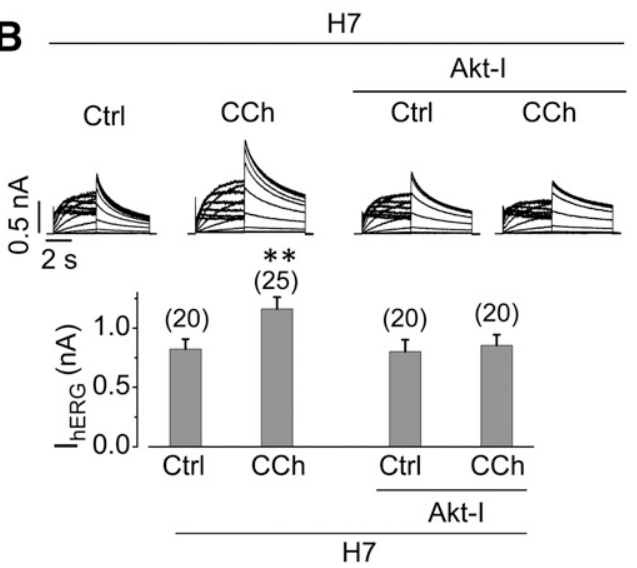

C

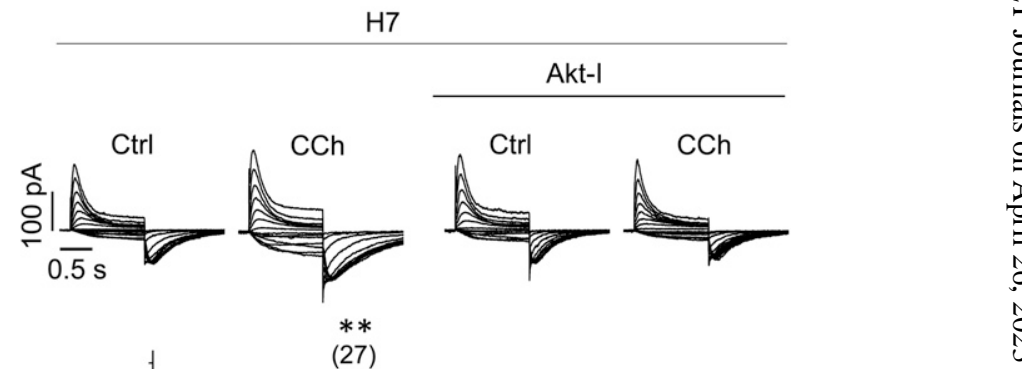

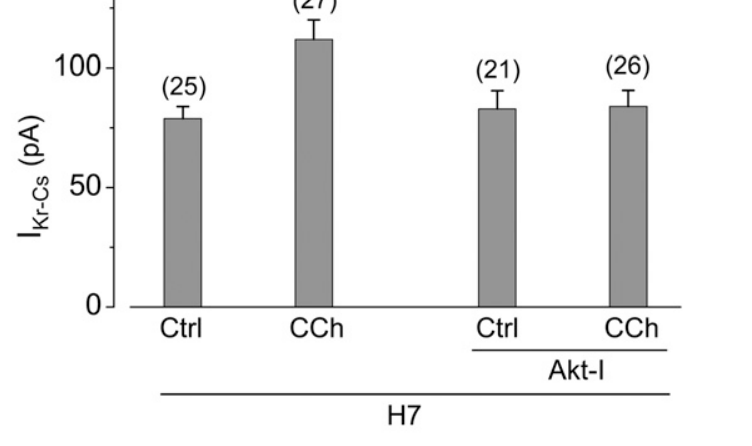

Fig. 10. CCh increases hERG and native $\mathrm{I}_{\mathrm{Kr}}$ in the presence of $\mathrm{H} 7$, and its effects are blocked by Akt-I. (A) Effects of CCh (50 $\mu \mathrm{M}, 24$ hours) on hERG expression in H7-treated cells in the absence or presence of Akt-I $(n=4)$. (B) Effects of CCh $(50 \mu \mathrm{M}, 24$ hours $)$ on $\mathrm{I}_{\mathrm{hERG}}$ in $50 \mu \mathrm{M}$ H7-treated cells in the absence or presence of Akt-I $(2.5 \mu \mathrm{M})$. The numbers above the bar graphs indicate the number of cells examined from four independent experiments. (C) Effects of CCh $\left(50 \mu \mathrm{M}, 24\right.$ hours) on $\mathrm{Cs}^{+}$-mediated $\mathrm{I}_{\mathrm{Kr}}\left(\mathrm{I}_{\mathrm{Kr}-\mathrm{Cs}}\right)$ in H7-treated neonatal rat ventricular myocytes in the absence or presence of Akt-I. The numbers above the bar graphs indicate the number of cells examined from five independent experiments. ${ }^{* *} P<0.01$ versus control (Ctrl). 
The arrestin-biased M3 designer-receptor exclusively activated by CNO (M3D-arr) provides a powerful means for the investigation of $\beta$-arrestin signaling in the absence of $\mathrm{G}_{\mathrm{q}}$ protein activity (Nakajima and Wess, 2012). It has been demonstrated that CNO activation of the M3D-arr is unable to stimulate a $\mathrm{G}$ protein(q)-coupled response but can stimulate $\beta$-arrestin signaling (Nakajima and Wess, 2012). It is noted that although CNO preferentially targets a mutant M3 receptor, M3D-arr, it does not produce functional selectivity regarding the signaling pathways associated with M3 receptor activation (Alvarez-Curto et al., 2011). The $\beta$-arrestin-biased signaling of M3D-arr results from a mutation within the receptor that selectively uncouples $\mathrm{G}_{\mathrm{q}}$ proteins but preserves $\beta$-arrestin signaling (Nakajima and Wess, 2012). Indeed, the $\beta$-arrestin signaling-mediated increase in hERG// $\mathrm{I}_{\mathrm{Kr}}$ was also observed in hERG-HEK cells and in neonatal ventricular myocytes upon activation of endogenous $\mathrm{M} 3$ receptors by $\mathrm{CCh}$ when the $\mathrm{G}$ protein-coupled response was blocked by $\mathrm{H} 7$ (Fig. 10).

Upon ligand-binding, G protein-coupled receptor kinases phosphorylate Ser-Thr residues in the cytoplasmic C-terminus of GPCRs to promote $\beta$-arrestin recruitment (Oakley et al., 2001; Reiter and Lefkowitz, 2006). Many GPCRs have been identified to recruit and interact with $\beta$-arrestin at the plasma membrane (Ahn et al., 2004; Novi et al., 2005; Shenoy et al., 2006). In the context of M3 receptors, stimulation by $\mathrm{CCh}$ promotes the recruitment and interaction with $\beta$-arrestin- 1 (Novi et al., 2005). Our data show that, following stimulation by CNO, M3D-arr selectively interacts with $\beta$-arrestin-1, but not $\beta$-arrestin-2 (Figs. 4 and 5). We further demonstrated that M3Darr and $\beta$-arrestin- 1 colocalize at or near the plasma membrane (Fig. 5), indicating that $\beta$-arrestin-1 is primarily recruited to stimulated M3D-arr receptors.

Activation of $\mathrm{M} 3$ receptors elicits $\mathrm{G}_{\mathrm{q}}$ protein-dependent (PKC) and independent ( $\beta$-arrestin) pathways (Nakajima and Wess, 2012). While our previous (Wang et al., 2014) and present studies indicate that both pathways regulate hERG expression via distinct mechanisms, the proportional contribution of each pathway to the increased hERG expression is complex and remains to be elucidated in future studies. This is partially due to the observations that there is a difference in response time between $G_{q}$ protein and $\beta$-arrestin signaling-mediated hERG modulation. We previously demonstrated that CCh-mediated activation of M3 receptors increases mature hERG expression and $I_{h E R G}$. The CCh-mediated increase occurs in 2 hours and becomes obvious at 8 hours (Wang et al., 2014), and is blocked by the PKC inhibitor H7 (Wang et al., 2014). On the other hand, in the present study we found that the CNO-induced increase in mature hERG expression displayed a slow onset and became obvious at 24 hours (Fig. 1), and the effect could not be blocked by $\mathrm{H} 7$ (Fig. 6A). These data indicate that our previously observed 8-hour CCh-mediated hERG increase is mainly due to activation of the $\mathrm{G}$ protein-dependent PKC pathway (Wang et al., 2014), in which the G proteinindependent $\beta$-arrestin pathway had not sufficiently developed.

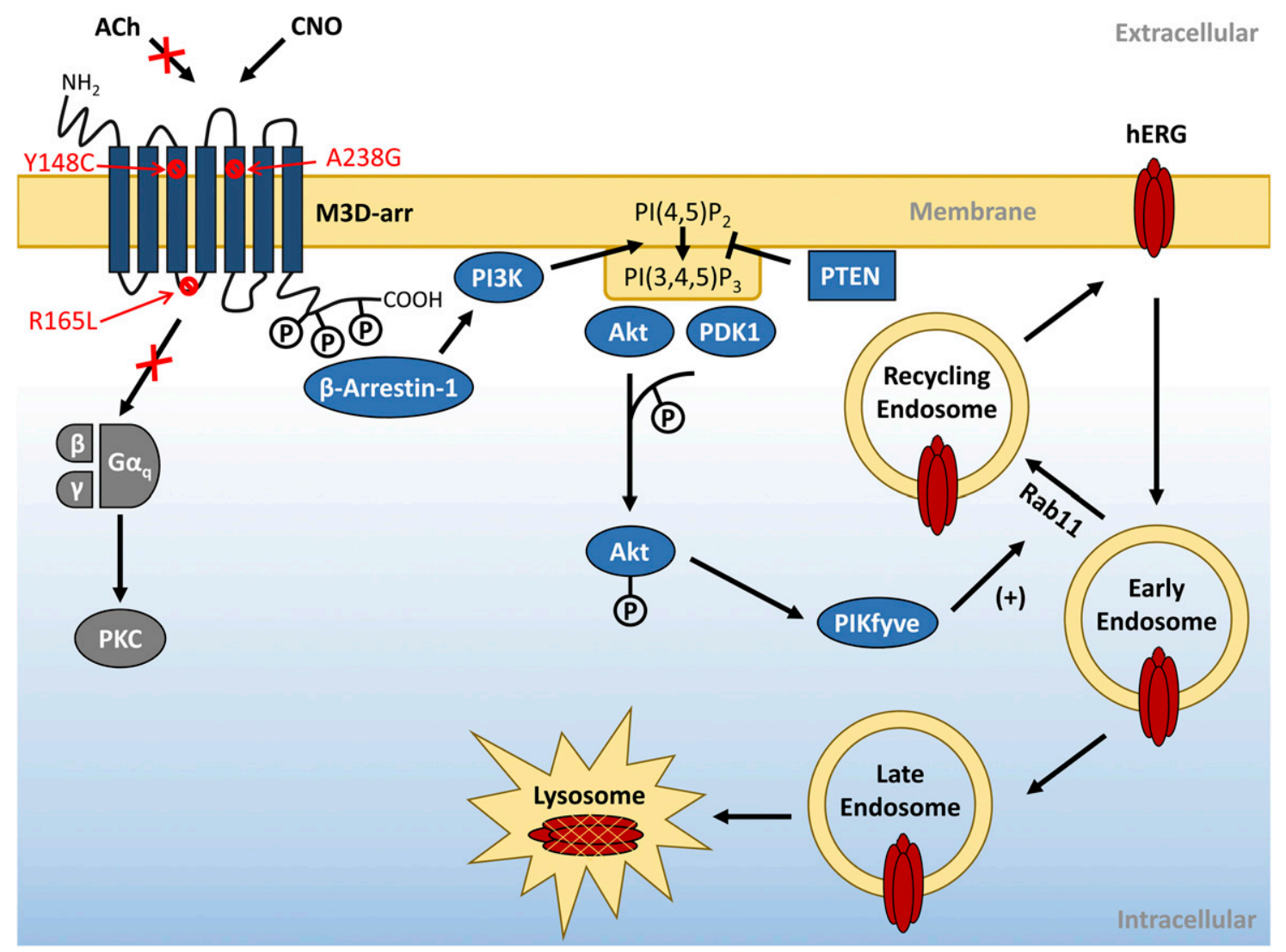

Fig. 11. Illustration of M3D-arr-mediated $\beta$-arrestin signaling in hERG regulation. Activation of M3D-arr by CNO leads to the recruitment of $\beta$-arrestin1 , which promotes PI3K-dependent activation of Akt. Enhancement of Akt activity stimulates PIKfyve which promotes Rab11-mediated hERG recycling, leading to an increased mature hERG expression. 
In the present study, our data show that the 24-hour CNOtreatment induces similar increases in hERG expression in hERG-HEK cells without $\mathrm{H} 7$ or with $\mathrm{H} 7$ treatment (Fig. 6A). Moreover, the 24-hour CCh-induced hERG increase was prevented by the Akt inhibitor Akt-I (Fig. 10, A and B). We previously showed that a 24-hour treatment of neonatal rat ventricular myocytes with CCh $(50 \mu \mathrm{M})$ in the absence of $\mathrm{H} 7$ increased $\mathrm{I}_{\mathrm{Kr}}$ (Wang et al., 2014). In the present study, we performed similar experiments in neonatal rat ventricular myocytes with inclusion of $\mathrm{H} 7$ to block the $\mathrm{G}$ proteindependent signaling pathway. Interestingly, CCh-treatment induced $\mathrm{I}_{\mathrm{Kr}}$ increase in the presence of $\mathrm{H} 7$ (present study, Fig. 10C) is not different from that in the absence of $\mathrm{H} 7$ (Fig. 8C of previous study) (Wang et al., 2014). Furthermore, the effect of the 24-hour CCh-treatment on $\mathrm{I}_{\mathrm{Kr}}$ was abolished by Akt-I (Fig. 10C). These data suggest the 24-hour CCh-mediated $\mathrm{I}_{\mathrm{Kr}}$ increase is primarily mediated through the $\beta$-arrestin signaling pathway. It has been shown that the $\beta$-arrestin and $\mathrm{G}_{\mathrm{q}}$ protein-signaling pathways are independent of each other (Ahn et al., 2004; Shenoy et al., 2006). For example, regarding ERK1/2 activation following angiotensin II type 1 receptor stimulation, $\beta$-arrestin-mediated ERK1/2 activation is slow, whereas G protein-mediated activation is rapid (Ahn et al., 2004). Thus, it is likely that M3 receptor stimulation increases mature hERG expression through temporally distinct signaling mechanisms: an early $\mathrm{G}_{\mathrm{q}}$ protein-dependent pathway and a late $\beta$-arrestin-dependent pathway. The existence of temporally distinct signaling mechanisms is interesting and provides novel insights into the sophisticated cellular regulatory systems that offer flexibility in hERG regulation.

Our data show that Akt plays a key role in the CNO/M3Darr mediated $\beta$-arrestin signaling pathway. Inhibition of Akt abolished the CNO-induced increase in mature hERG expression (Fig. 6B). An increase in active (phosphorylated) Akt expression paralleled the increase in mature hERG expression following CNO treatment (Fig. 7A). Furthermore, activation of Akt by the small-molecule activator, SC79, increased the expression of phosphorylated Akt and mature hERG expression (Fig. 7B) and $\mathrm{I}_{\mathrm{hERG}}$ (Fig. 7C).

Akt is modulated through a variety of upstream regulators. Of notable interest is the lipid kinase PI3K, a well-known activator of Akt that is constitutively expressed in the heart and vasculature (Crackower et al., 2002; Oudit et al., 2004). PI3K phosphorylates phosphatidylinositol 4,5-bisphosphate to produce PtdIns $(3,4,5) P_{3}$, a phospholipid responsible for the selective recruitment of downstream effectors to the plasma membrane. By binding to a common pleckstrin homology domain, PtdIns $(3,4,5) P_{3}$ associates phosphoinositide-dependent kinase-1 with various kinase substrates such as Akt to facilitate their activation (Alessi et al., 1997; Bellacosa et al., 1998). The activity of PI3K is antagonized by the lipid phosphatase, PTEN, which opposes production of $\operatorname{PtdIns}(3,4,5) P_{3}$ (Maehama and Dixon, 1998). Our data showed that inhibition of Akt activation by PTEN overexpression abolished the CNO-induced increase in hERG expression and $\mathrm{I}_{\mathrm{hERG}}$ in M3D-arr-transfected hERGHEK cells (Fig. 8), suggesting that enhancement of Akt activity during this process occurs primarily through PI3K. The activity of PI3K is enhanced by tyrosine phosphorylation of its regulatory subunit, which relieves inhibition of its catalytic domain (Cuevas et al., 2001). While this study does not evaluate the mechanism of PI3K activation, $\beta$-arrestin is known to scaffold nonreceptor tyrosine kinases that may lead to its phosphorylation (Luttrell et al., 1999).

Channel recycling contributes to the homeostasis of hERG expression level in the plasma membrane (Chen et al., 2015). PIKfyve phosphorylates phosphatidylinositol 3-phosphate to produce phosphatidylinositol 3,5-bisphosphate, a phospholipid implicated in the stability of trafficking vesicles (Berwick et al., 2004). Akt-mediated activation of PIKfyve increases phosphatidylinositol 3,5-bisphosphate production on the surface of intracellular vesicles, which subsequently modulates trafficking (Berwick et al., 2004). Pakladok et al. (2013) showed that enhanced Akt and PIKfyve activity increases hERG current. Our data are consistent with this notion, showing that PIKfyve inhibition attenuates the effect of CNO-mediated activation of M3D-arr on $\mathrm{I}_{\mathrm{hERG}}$ (Fig. 9). Therefore, increases in hERG expression and current are likely a result of enhanced vesicle trafficking to the plasma membrane.

We recently found that Rab11 maintains homeostatic levels of mature hERG expression by facilitating recycling of channels to the cell surface (Chen et al., 2015). Previous studies have shown that activation of PIKfyve positively regulates Rab11mediated transport of hERG and KCNQ1/KCNE1 channels to the membrane (Pakladok et al., 2013; Seebohm et al., 2007). Therefore, Rab11 is likely involved in the M3D-arr activationinduced increase in hERG expression and function. Our results are consistent with this notion, showing that overexpression of a Rab11 DN mutant abolishes the effect of CNO-mediated activation of M3D-arr on $\mathrm{I}_{\mathrm{hERG}}$ (Fig. 9). Rab11 DN also decreased $\mathrm{I}_{\text {hERG }}$ (Fig. 9), confirming that Rab11 contributes to the homeostasis of hERG expression in the plasma membrane (Chen et al., 2015).

PI3K/Akt cascades can be activated by insulin- or insulinlike growth factor 1 receptor signaling or other serum growth factors (Shepherd et al., 1998; Povsic et al., 2003). It has been reported that $\beta$-arrestin-1 mediates insulin-like growth factor 1 activation of PI3K and anti-apoptosis (Povsic et al., 2003). In a previous study focusing on the role of SGK in hERG regulation, we demonstrated that activation of SGK by overexpressing the SGK1 or SGK3 plasmid in hERG-HEK cells or applying serum, dexamethasone, or insulin to the culture medium increases mature hERG expression partially through promoting Rab11-mediated hERG recycling (Lamothe and Zhang, 2013). SGK and Akt are closely related enzymes and share an overlapping set of substrates (Sommer et al., 2013). While our previous study did not elucidate the specific roles of SGK and Akt, these data are consistent with our present finding that activation of PI3K/Akt cascades upregulate trafficking of the hERG channels.

In summary, we demonstrated a novel mechanism of $\beta$-arrestin-dependent regulation of hERG channels (Fig. 11). CNO-mediated activation of M3D-arr leads to the recruitment of $\beta$-arrestin-1, promoting PI3K-dependent activation of Akt. Enhancement of Akt activity stimulates PIKfyve, which promotes Rab11-mediated hERG recycling to the membrane (Fig. 11). These findings provide novel insight into hERG regulation, which is useful for understanding impaired hERG function and identifying therapeutic targets in the treatment of LQTS. In addition, the cellular signaling pathways identified using hERG regulation in the present study extend our understanding of molecular mechanisms underlying the regulation of other molecules involved in various cellular functions. 


\section{Authorship Contributions}

Participated in research design: Sangoi, Lamothe, Fisher, Zhang. Conducted experiments: Sangoi, Lamothe, Guo, Yang, Li, Avery. Performed data analysis: Sangoi, Lamothe, Guo, Yang, Li. Wrote or contributed to the writing of the manuscript: Sangoi, Lamothe, Zhang.

\section{References}

Ahn S, Shenoy SK, Wei H, and Lefkowitz RJ (2004) Differential kinetic and spatial patterns of $\beta$-arrestin and G protein-mediated ERK activation by the angiotensin II receptor. J Biol Chem 279:35518-35525.

Alessi DR, James SR, Downes CP, Holmes AB, Gaffney PR, Reese CB, and Cohen P (1997) Characterization of a 3-phosphoinositide-dependent protein kinase which phosphorylates and activates protein kinase B $\alpha$. Curr Biol 7:261-269.

Alvarez-Curto E, Prihandoko R, Tautermann CS, Zwier JM, Pediani JD, Lohse MJ, Hoffmann C, Tobin AB, and Milligan G (2011) Developing chemical genetic approaches to explore $\mathrm{G}$ protein-coupled receptor function: validation of the use of a receptor activated solely by synthetic ligand (RASSL). Mol Pharmacol 80 1033-1046.

Anderson CL, Delisle BP, Anson BD, Kilby JA, Will ML, Tester DJ, Gong Q, Zhou Z, Ackerman MJ, and January CT (2006) Most LQT2 mutations reduce Kv11.1 (hERG) current by a class 2 (trafficking-deficient) mechanism. Circulation 113: 365-373.

Armbruster BN, Li X, Pausch MH, Herlitze S, and Roth BL (2007) Evolving the lock to fit the key to create a family of G protein-coupled receptors potently activated by an inert ligand. Proc Natl Acad Sci USA 104:5163-5168.

Attramadal H, Arriza JL, Aoki C, Dawson TM, Codina J, Kwatra MM, Snyder SH, Caron MG, and Lefkowitz RJ (1992) $\beta$-Arrestin2, a novel member of the arrestin/ $\beta$-arrestin gene family. J Biol Chem 267:17882-17890.

Bellacosa A, Chan TO, Ahmed NN, Datta K, Malstrom S, Stokoe D, McCormick F, Feng J, and Tsichlis P (1998) Akt activation by growth factors is a multiple-step process: the role of the $\mathrm{PH}$ domain. Oncogene 17:313-325.

Berwick DC, Dell GC, Welsh GI, Heesom KJ, Hers I, Fletcher LM, Cooke FT, and Tavaré JM (2004) Protein kinase B phosphorylation of PIKfyve regulates the trafficking of GLUT4 vesicles. J Cell Sci 117:5985-5993.

Chen J, Guo J, Yang T, Li W, Lamothe SM, Kang Y, Szendrey JA, and Zhang S (2015) Rab11-dependent recycling of the human ether-a-go-go-related gene (hERG) channel. J Biol Chem 290:21101-21113.

Crackower MA, Oudit GY, Kozieradzki I, Sarao R, Sun H, Sasaki T, Hirsch E, Suzuki A, Shioi T, Irie-Sasaki J, et al. (2002) Regulation of myocardial contractility and cell size by distinct PI3K-PTEN signaling pathways. Cell 110:737-749.

Cuevas BD, Lu Y, Mao M, Zhang J, LaPushin R, Siminovitch K, and Mills GB (2001) Tyrosine phosphorylation of p85 relieves its inhibitory activity on phosphatidylinositol 3-kinase. J Biol Chem 276:27455-27461.

Curran ME, Splawski I, Timothy KW, Vincent GM, Green ED, and Keating MT (1995) A molecular basis for cardiac arrhythmia: HERG mutations cause long QT syndrome. Cell 80:795-803.

de Lartigue J, Polson H, Feldman M, Shokat K, Tooze SA, Urbé S, and Clague MJ (2009) PIKfyve regulation of endosome-linked pathways. Traffic 10:883-893.

Dennis A, Wang L, Wan X, and Ficker E (2007) hERG channel trafficking: novel targets in drug-induced long QT syndrome. Biochem Soc Trans 35:1060-1063.

Eglen RM (2012) Overview of muscarinic receptor subtypes. Handb Exp Pharmacol 208:3-28.

Gianulis EC and Trudeau MC (2011) Rescue of aberrant gating by a genetically encoded PAS (Per-Arnt-Sim) domain in several long QT syndrome mutant human ether-á-go-go-related gene potassium channels. J Biol Chem 286:22160-22169.

Gong Q, Anderson CL, January CT, and Zhou Z (2002) Role of glycosylation in cell surface expression and stability of HERG potassium channels. Am J Physiol Heart Circ Physiol 283:H77-H84.

Goodman OB, Jr, Krupnick JG, Santini F, Gurevich VV, Penn RB, Gagnon AW, Keen $\mathrm{JH}$, and Benovic JL (1996) $\beta$-Arrestin acts as a clathrin adaptor in endocytosis of the $\beta_{2}$-adrenergic receptor. Nature 383:447-450.

Guizzetti M and Costa LG (2001) Activation of phosphatidylinositol 3 kinase by muscarinic receptors in astrocytoma cells. Neuroreport 12:1639-1642.

Guo J, Massaeli H, Li W, Xu J, Luo T, Shaw J, Kirshenbaum LA, and Zhang S (2007) Identification of $\mathrm{I}_{\mathrm{Kr}}$ and its trafficking disruption induced by probucol in cultured neonatal rat cardiomyocytes. J Pharmacol Exp Ther 321:911-920.

Guo J, Massaeli H, Xu J, Jia Z, Wigle JT, Mesaeli N, and Zhang S (2009) Extracellular $\mathrm{K}^{+}$concentration controls cell surface density of $\mathrm{I}_{\mathrm{Kr}}$ in rabbit hearts and of the HERG channel in human cell lines. J Clin Invest 119:2745-2757.

Guo J, Wang T, Li X, Shallow H, Yang T, Li W, Xu J, Fridman MD, Yang X, and Zhang S (2012) Cell surface expression of ether-a-go-go-related gene (hERG) channels is regulated by caveolin-3 via the ubiquitin ligase Nedd4-2. J Biol Chem 287:33132-33141.

Hermans E (2003) Biochemical and pharmacological control of the multiplicity of coupling at G-protein-coupled receptors. Pharmacol Ther 99:25-44.

Kang Y, Guo J, Yang T, Li W, and Zhang S (2015) Regulation of the human ether-ago-go-related gene (hERG) potassium channel by Nedd4 family interacting proteins (Ndfips). Biochem $J$ 472:71-82.

Keating MT and Sanguinetti MC (2001) Molecular and cellular mechanisms of cardiac arrhythmias. Cell 104:569-580.

Kuryshev YA, Ficker E, Wang L, Hawryluk P, Dennis AT, Wible BA, Brown AM, Kang J, Chen XL, Sawamura K, et al. (2005) Pentamidine-induced long QT syndrome and block of hERG trafficking. J Pharmacol Exp Ther 312:316-323.

Lamothe SM, Guo J, Li W, Yang T, and Zhang S (2016) The human ether-a-go-gorelated gene (hERG) potassium channel represents an unusual target for proteasemediated damage. J Biol Chem 291:20387-20401.
Lamothe SM and Zhang S (2013) The serum- and glucocorticoid-inducible kinases SGK1 and SGK3 regulate hERG channel expression via ubiquitin ligase Nedd4-2 and GTPase Rab11. J Biol Chem 288:15075-15084

Lee DK, Nguyen T, Lynch KR, Cheng R, Vanti WB, Arkhitko O, Lewis T, Evans JF, George SR, and O'Dowd BF (2001) Discovery and mapping of ten novel G proteincoupled receptor genes. Gene 275:83-91.

Livak KJ and Schmittgen TD (2001) Analysis of relative gene expression data using real-time quantitative PCR and the $2^{-\Delta \Delta C T}$ method. Methods 25:402-408.

Luttrell LM, Ferguson SS, Daaka Y, Miller WE, Maudsley S, Della Rocca GJ, Lin F, Kawakatsu H, Owada K, Luttrell DK, et al. (1999) $\beta$-Arrestin-dependent formation of $\beta_{2}$ adrenergic receptor-Src protein kinase complexes. Science 283: $655-661$.

Luttrell LM, Roudabush FL, Choy EW, Miller WE, Field ME, Pierce KL, and Lefkowitz RJ (2001) Activation and targeting of extracellular signal-regulated kinases by $\beta$-arrestin scaffolds. Proc Natl Acad Sci USA 98:2449-2454.

Maehama T and Dixon JE (1998) The tumor suppressor, PTEN/MMAC1, dephosphorylates the lipid second messenger, phosphatidylinositol 3,4,5-trisphosphate. $J$ Biol Chem 273:13375-13378.

McEwen RK, Dove SK, Cooke FT, Painter GF, Holmes AB, Shisheva A, Ohya Y, Parker PJ, and Michell RH (1999) Complementation analysis in PtdIns $P$ kinasedeficient yeast mutants demonstrates that Schizosaccharomyces pombe and murine Fab1p homologues are phosphatidylinositol 3-phosphate 5-kinases. J Biol Chem 274:33905-33912.

Milburn CC, Deak M, Kelly SM, Price NC, Alessi DR, and Van Aalten DM (2003) Binding of phosphatidylinositol 3,4,5-trisphosphate to the pleckstrin homology domain of protein kinase $\mathrm{B}$ induces a conformational change. Biochem $J$ 375: 531-538

Nakajima K and Wess J (2012) Design and functional characterization of a novel, arrestin-biased designer G protein-coupled receptor. Mol Pharmacol 82:575-582.

Noma T, Lemaire A, Naga Prasad SV, Barki-Harrington L, Tilley DG, Chen J, Le Corvoisier P, Violin JD, Wei H, Lefkowitz RJ, et al. (2007) $\beta$-Arrestin-mediated $\beta_{1}$-adrenergic receptor transactivation of the EGFR confers cardioprotection. $J$ Clin Invest 117:2445-2458.

Novi F, Stanasila L, Giorgi F, Corsini GU, Cotecchia S, and Maggio R (2005) Paired activation of two components within muscarinic $\mathrm{M}_{3}$ receptor dimers is required for recruitment of $\beta$-arrestin-1 to the plasma membrane. $J$ Biol Chem 280 : 19768-19776.

Oakley RH, Laporte SA, Holt JA, Barak LS, and Caron MG (2001) Molecular determinants underlying the formation of stable intracellular $\mathrm{G}$ protein-coupled receptor- $\beta$-arrestin complexes after receptor endocytosis. $J$ Biol Chem $\mathbf{2 7 6}$ : 19452-19460.

Oakley RH, Laporte SA, Holt JA, Caron MG, and Barak LS (2000) Differential affinities of visual arrestin, $\beta$ arrestin 1 , and $\beta$ arrestin 2 for $\mathrm{G}$ protein-coupled receptors delineate two major classes of receptors. J Biol Chem 275:17201-17210.

Oudit GY and Penninger JM (2009) Cardiac regulation by phosphoinositide 3-kinases and PTEN. Cardiovasc Res 82:250-260.

Oudit GY, Sun H, Kerfant BG, Crackower MA, Penninger JM, and Backx PH (2004) The role of phosphoinositide-3 kinase and PTEN in cardiovascular physiology and disease. J Mol Cell Cardiol 37:449-471.

Pakladok T, Almilaji A, Munoz C, Alesutan I, and Lang F (2013) PIKfyve sensitivity of hERG channels. Cell Physiol Biochem 31:785-794.

Pals-Rylaarsdam R, Gurevich VV, Lee KB, Ptasienski JA, Benovic JL, and Hosey MM (1997) Internalization of the $\mathrm{m} 2$ muscarinic acetylcholine receptor. Arrestinindependent and -dependent pathways. J Biol Chem 272:23682-23689.

Povsic TJ, Kohout TA, and Lefkowitz RJ (2003) $\beta$-Arrestin1 mediates insulin-like growth factor 1 (IGF-1) activation of phosphatidylinositol 3-kinase (PI3K) and antiapoptosis. J Biol Chem 278:51334-51339.

Rajamani S, Anderson CL, Valdivia CR, Eckhardt LL, Foell JD, Robertson GA, Kamp TJ, Makielski JC, Anson BD, and January CT (2006) Specific serine proteases selectively damage KCNH2 (hERG1) potassium channels and $I_{\mathrm{Kr}}$. Am J Physiol Heart Circ Physiol 290:H1278-H1288.

Reiter E and Lefkowitz RJ (2006) GRKs and $\beta$-arrestins: roles in receptor silencing, trafficking and signaling. Trends Endocrinol Metab 17:159-165.

Roden DM (2004) Drug-induced prolongation of the QT interval. N Engl J Med 350: $1013-1022$

Sanguinetti MC, Jiang C, Curran ME, and Keating MT (1995) A mechanistic link between an inherited and an acquired cardiac arrhythmia: HERG encodes the $\mathrm{I}_{K_{r}}$ potassium channel. Cell 81:299-307.

Seebohm G, Strutz-Seebohm N, Birkin R, Dell G, Bucci C, Spinosa MR, Baltaev R, Mack AF, Korniychuk G, Choudhury A, et al. (2007) Regulation of endocytic recycling of KCNQ1/KCNE1 potassium channels. Circ Res 100:686-692.

Shah RR (2005) Drugs, QTc interval prolongation and final ICH E14 guideline : an important milestone with challenges ahead. Drug Saf 28:1009-1028.

Shenoy SK, Drake MT, Nelson CD, Houtz DA, Xiao K, Madabushi S, Reiter E, Premont RT, Lichtarge O, and Lefkowitz RJ (2006) $\beta$-Arrestin-dependent, G protein-independent ERK1/2 activation by the $\beta 2$ adrenergic receptor. $J$ Biol Chem 281:1261-1273.

Shepherd PR, Withers DJ, and Siddle K (1998) Phosphoinositide 3-kinase: the key switch mechanism in insulin signalling. Biochem $J$ 333:471-490.

Sommer EM, Dry H, Cross D, Guichard S, Davies BR, and Alessi DR (2013) Elevated SGK1 predicts resistance of breast cancer cells to Akt inhibitors. Biochem J 452: 499-508.

Stephens L, Anderson K, Stokoe D, Erdjument-Bromage H, Painter GF, Holmes AB Gaffney PR, Reese CB, McCormick F, Tempst P, et al. (1998) Protein kinase B kinases that mediate phosphatidylinositol 3,4,5-trisphosphate-dependent activation of protein kinase B. Science 279:710-714

Sterne-Marr R, Gurevich VV, Goldsmith P, Bodine RC, Sanders C, Donoso LA and Benovic JL (1993) Polypeptide variants of $\beta$-arrestin and arrestin3. J Biol Chem 268:15640-15648. 
Takeda S, Kadowaki S, Haga T, Takaesu H, and Mitaku S (2002) Identification of G protein-coupled receptor genes from the human genome sequence. FEBS Lett 520: 97-101.

Thiel G, Kaufmann A, and Rössler OG (2013) G-protein-coupled designer receptorsnew chemical-genetic tools for signal transduction research. Biol Chem 394: $1615-1622$.

Trudeau MC, Warmke JW, Ganetzky B, and Robertson GA (1995) HERG, a human inward rectifier in the voltage-gated potassium channel family. Science 269: 92-95.

Wang T, Hogan-Cann A, Kang Y, Cui Z, Guo J, Yang T, Lamothe SM, Li W, Ma A Fisher JT, et al. (2014) Muscarinic receptor activation increases hERG channel expression through phosphorylation of ubiquitin ligase Nedd4-2. Mol Pharmacol 85:877-886.

Wess J (2016) Use of designer G protein-coupled receptors to dissect metabolic pathways. Trends Endocrinol Metab 27:600-603.
Wess J, Nakajima K, and Jain S (2013) Novel designer receptors to probe GPCR signaling and physiology. Trends Pharmacol Sci 34:385-392.

Zhang $\mathrm{S}(2006)$ Isolation and characterization of $I_{\mathrm{Kr}}$ in cardiac myocytes by $\mathrm{Cs}^{+}$ permeation. Am J Physiol Heart Circ Physiol 290:H1038-H1049.

Zhang Y, Wang H, Wang J, Han H, Nattel S, and Wang Z (2003) Normal function of HERG $\mathrm{K}^{+}$channels expressed in HEK293 cells requires basal protein kinase B activity. FEBS Lett 534:125-132.

Zhou Z, Gong Q, Epstein ML, and January CT (1998) HERG channel dysfunction in human long QT syndrome. Intracellular transport and functional defects. J Biol Chem 273:21061-21066.

Address correspondence to: Dr. Shetuan Zhang, Department of Biomedical and Molecular Sciences, Queen's University, 18 Stuart Street, Kingston, ON, K7L 3N6 Canada. E-mail: shetuan.zhang@queensu.ca 